\title{
Eugenol, a promising building block for biobased polymers with cutting-edge properties
}

\author{
Roberto MORALES-CERRADA, Samantha MOLINA-GUTIERREZ, Patrick LACROIX-DESMAZES, \\ Sylvain CAILLOL* \\ ICGM, Univ Montpellier, CNRS, ENSCM, Montpellier, France \\ *Corresponding author: sylvain.caillol@enscm.fr
}

\begin{abstract}
Biobased materials, derived from biomass building blocks, are essential in the pursuit of sustainable materials. Eugenol, a natural phenol obtained from clove oil, but also from lignin depolymerization, possesses a chemical structure that allows its easy modification to obtain a broad and versatile platform of biobased monomers. In this review, an overview of the variety of reactions that have been executed on the allylic double bond, phenol hydroxyl group, aromatic ring and methoxy group is given, focusing our attention on those to obtain monomers suitable for different polymerization reactions. Furthermore, possible applications and perspectives on the eugenol-derived materials are provided.
\end{abstract}

\section{TABLE OF CONTENTS}

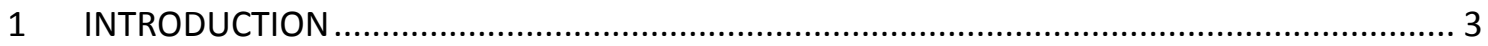

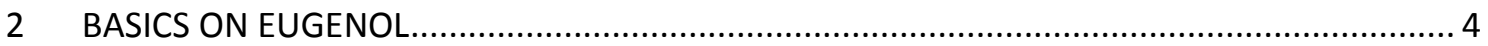

2.1 Origins, abundance and market ........................................................................... 4

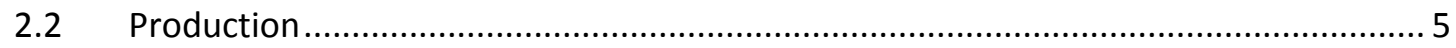

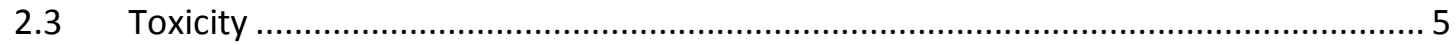

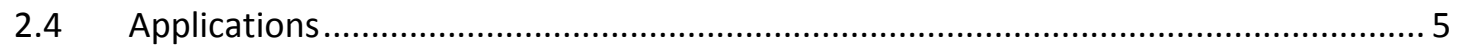

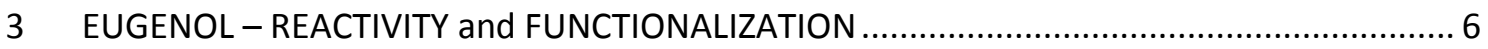

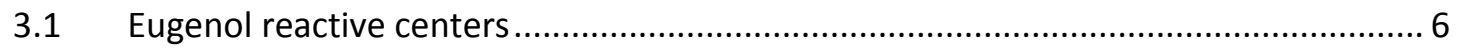

3.2 Allylic double bond functionalization ......................................................................... 7

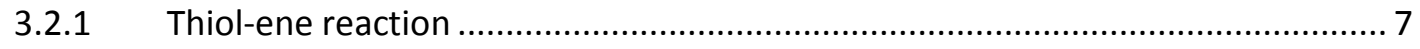

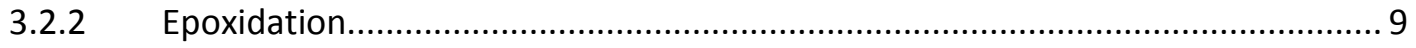

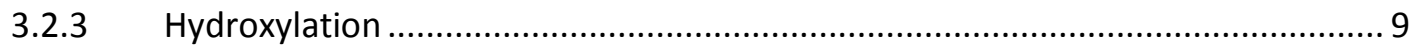

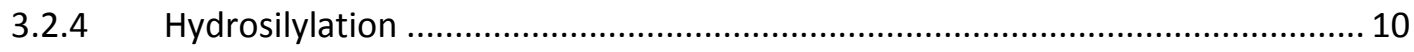

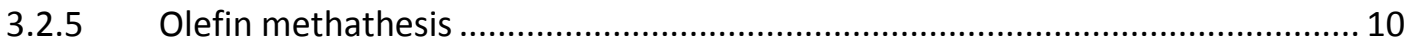




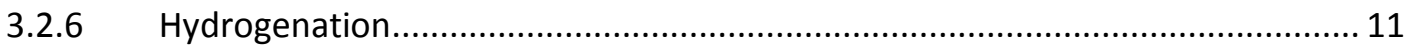

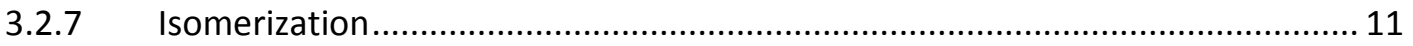

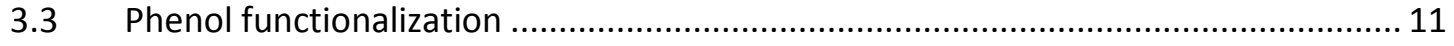

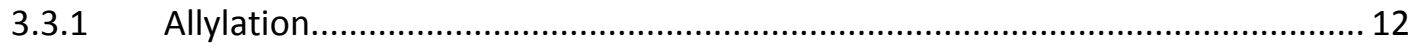

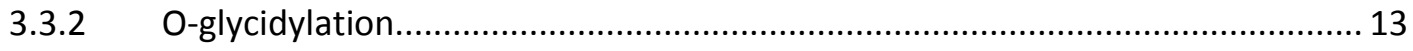

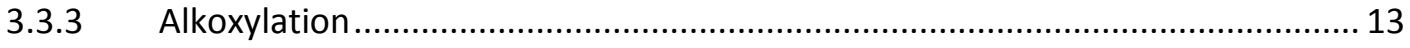

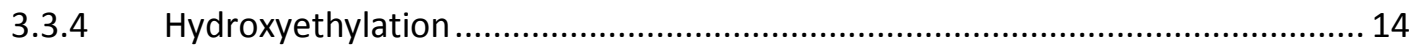

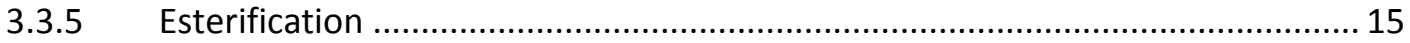

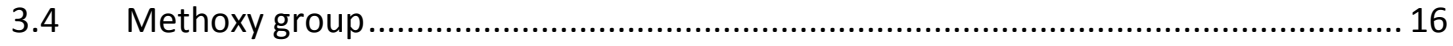

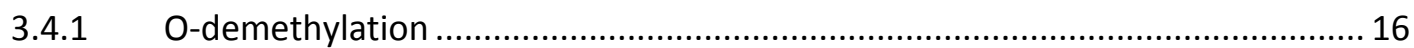

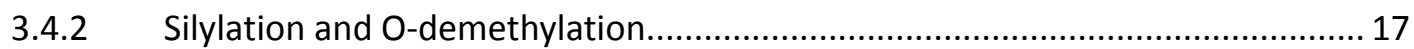

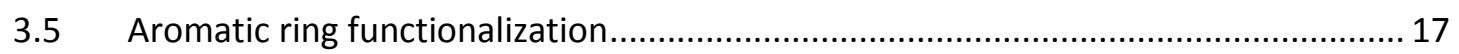

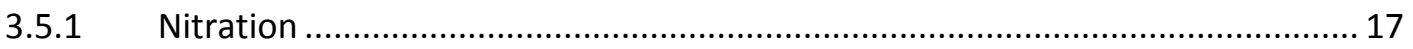

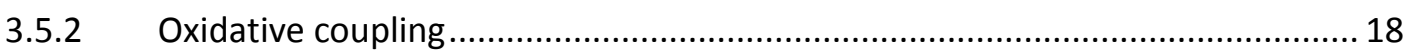

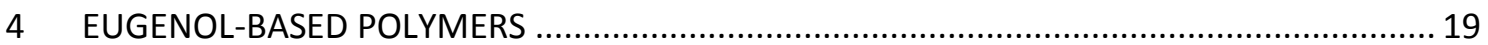

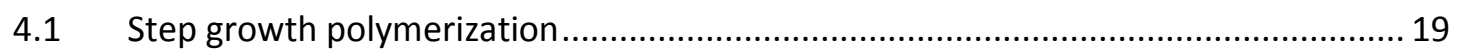

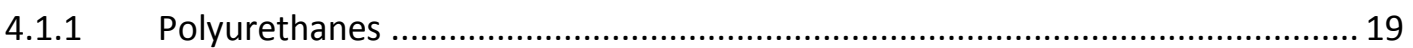

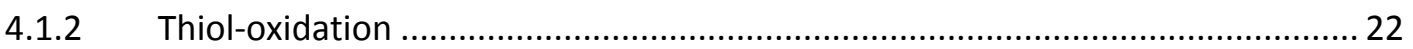

4.1.3 Thiol-ene coupling and thiol-ene polymerization ............................................. 23

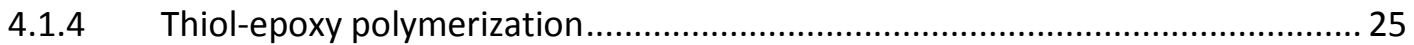

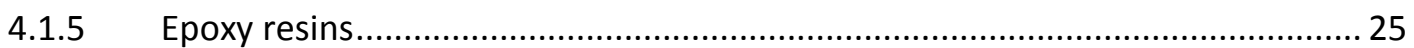

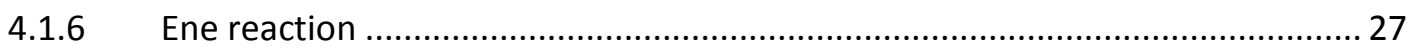

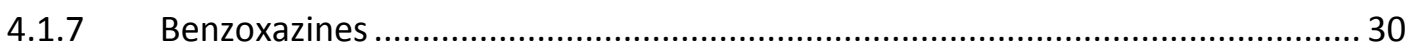

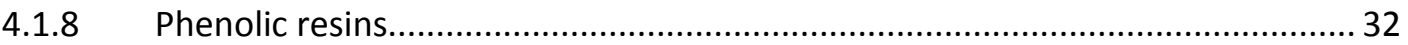

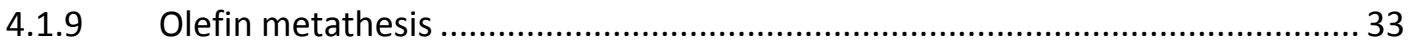

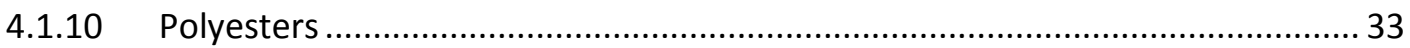

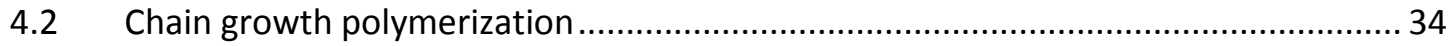

4.2.1 Cationic polymerization of eugenol ................................................................... 34

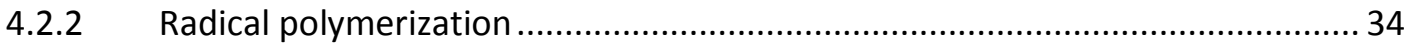

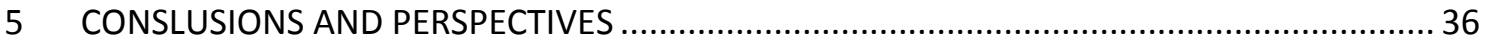

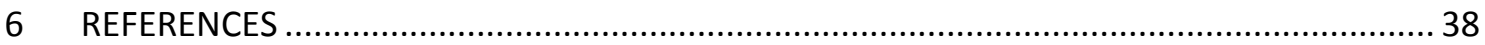




\section{INTRODUCTION}

The current environmental concerns related to the anthropogenic carbon emissions and waste production, as well as the increased social awareness and restrictive legislations, have led the scientific community to aim for more sustainable raw materials. This has been further promoted due to the volatility of conventional fossil fuel price, its possible shortage and hence supply issues in the near future. Thus, the interest in replacing fossil fuels with renewable resources has increased during the recent years. ${ }^{1}$

The objective of replacing petroleum-based molecules for biobased ones is to produce more sustainable materials. Specifically, polymers are remarkably interesting as they are materials with a wide range of applications because of their unique properties. However, the polymer industry is still mainly depending on petrochemical resources. It consumed around $4 \%$ of the world oil and gas production in 2009. ${ }^{2,3}$ Biomass feedstock could be an eco-friendly substitute to petroleum-based raw materials as it allows obtaining a wide range of chemicals, ${ }^{4-7}$ including monomers for the synthesis of biobased polymers. Moreover, their production process may be more energy efficient than petroleum-based plastics processing, minimizing the carbon footprint. ${ }^{8}$ Consequently, biobased polymers have received the increasing attention of the scientific community in recent years. ${ }^{8-13}$

Biobased aliphatic polymers are produced from a large variety of renewable raw materials such as carbohydrates, and vegetable oils. For instance, polylactic acid (PLA) and polyhydroxyalkonate (PHA), two of the most common biobased polymers, are synthesized from carbohydrates. ${ }^{11,14}$ On the other hand, polyesters, polyamides and polyurethanes can be obtained from triglycerides (fatty acids) of some vegetable oils such as flax, soybean, castor, sunflower and canola oil. ${ }^{15}$ However, the presence of aromatic groups in the polymer chain could confer interesting properties to the materials such as higher chemical resistance, higher thermal stability and good thermomechanical properties. ${ }^{16}$ Hence, aromatic groups are highly desired in highperformance polymers for many applications in coatings, automotive, aeronautics, binders and composites. ${ }^{17}$ Indeed, the aromatic biobased molecules and phenolic derivatives are very present in many natural sources such as lignin, tannins or cashew nutshell liquid (CNSL). ${ }^{18}$ CNSL is a mixture of phenolic compounds substituted with a long unsaturated alkyl chain. ${ }^{19}$ The main component of CNLS is anacardic acid, but a thermal treatment followed by a distillation leads to a mixture containing about $90 \%$ of cardanol, which is a promising building block for biobased phenolic polymers. ${ }^{20}$ Tannins are also a polyphenolic biomolecules present in many plants and trees used to produce phenolic resins. ${ }^{21}$ On the other hand, lignin is an economical and eco-friendly raw material to obtain phenolic monomers because of its wide availability and it is not a part of the food chain since it is obtained from the non-edible part of the plants and wood. It is an amorphous polyphenolic macromolecule with a wide number of polar 
functional groups. ${ }^{22}$ Nevertheless, depolymerization is necessary to obtain monophenol monomers from both lignin ${ }^{23}$ and tannin.

As mentioned before, several phenolic molecules employed in the synthesis of biobased monomers such as phenol, vanillin, guaiacol, eugenol, syringol and their derivatives ${ }^{18,24}$ can be obtained from the lignin depolymerization. ${ }^{23,25}$ Among them, eugenol is a promising molecule for several applications because of its chemical structure. Eugenol can be obtained from different plants. ${ }^{26}$ Moreover, palm oil pyrolysis allows to obtain biobased phenolic monomers such as cresol, guaiacol, syringol and eugenol. ${ }^{18}$ In addition, palm wastes produced by the oil palm industry are rich in lignocellulose and hence they are a good source of phenolic compounds and glucose. $^{27-29}$

Eugenol is a low viscosity homogeneous liquid, composed by a single molecule, in contrast to cardanol which is a mixture of various molecules. ${ }^{19}$ It is usually obtained from clove oil, which contains from 70 to $90 \%$ of eugenol. Annually, around 6,000 metric tons of clove oil are produced. ${ }^{30}$ Eugenol market has grown significantly during the last years and is expected to grow with a Compound Annual Growth Rate (CAGR) of $8 \%$ from 2020 to $2025,{ }^{31}$ reaching over US\$ 745 million revenue by the end of $2026 .{ }^{32}$ Thus, due to its chemical structure, as well as the different sources from which it can be produced and its rising market, eugenol is an interesting natural precursor of phenol.

While there are a few reviews about eugenol, they are almost exclusively dedicated to its medical and pharmaceutical applications. ${ }^{26,33,34}$ To the best of our knowledge, there is not a general review about eugenol as monomer for the synthesis of biobased polymers yet. Only the use of eugenol as monomer for biobased epoxy resin has been reviewed previously by our research team. ${ }^{35}$ However, during the last years, there have been an increasing research focused on the functionalization of eugenol to synthesize monomers, and to execute their subsequent polymerization to produce biobased or partially biobased polymers. Thus, this review focuses on eugenol as building block for the synthesis of monomers and biobased polymers through different polymerization mechanisms.

\section{BASICS ON EUGENOL}

\subsection{Origins, abundance and market}

Eugenol is a phenolic compound present in a large variety of plants such as clove tree, cinnamon, tulsi, basil, peeper, oregano, thyme, and nutmeg, among many others. ${ }^{26,33}$, 34,36 It was firstly extracted from the buds and leaves of clove tree (Syzygium aromaticum (L.) Merr. \& L.M.Perry or Eugenia caryophyllata Thunb.), which is native to Maluku Islands in Indonesia. ${ }^{33}$ Clove oil contains high concentration of eugenol ${ }^{33,} 37$ which is responsible for the characteristic clove aroma of clove buds and leaves. Cloves 
are produced in Madagascar, Tanzania and Sri Lanka, among many other countries, but especially in Indonesia which produced more than the $77 \%$ of the global production in 2016 (over 180,000 metric tons). ${ }^{38}$ In fact, commercial eugenol is mainly obtained from clove oil, but it is also extracted from cinnamon leaf, bark oil and basil oil which also contain high concentrations of this molecule. ${ }^{33,36}$

\subsection{Production}

Eugenol can be synthetically produced by the allylation of guaiacol with allyl chloride, $^{33,39}$ but it is usually obtained from natural oil sources. There are various process to extract eugenol from the natural oils such as hydro distillation, ${ }^{40}$ solvent extraction, ${ }^{41}$ microwave-assisted extraction ${ }^{42}$ or supercritical $\mathrm{CO}_{2}$ extraction. ${ }^{43}$ However, the most common method to extract eugenol is steam distillation. ${ }^{26,33,34}$ This technique consists in the formation of the corresponding phenolic alkali salt with an aqueous solution of sodium or potassium hydroxide. Then, the non-soluble fraction which contains the non-phenolic molecules is extracted with a solvent or especially by steam distillation. Finally, the resulting alkali solution is acidified at low temperatures and then eugenol is purified by fractional distillation.

Moreover, eugenol can also be obtained from depolymerization of lignin. ${ }^{23,44-46}$ Even though this process remains to be optimized, it represents a promising feedstock due to the large availability of lignin.

\subsection{Toxicity}

The US Food \& Drug Administration (FDA) considers eugenol as "generally recognized as safe" (GRAS) and it allows the use of eugenol in food. ${ }^{47}$ However, chronic exposure may cause a certain cytotoxicity and genotoxicity, ${ }^{33}$ and the ingestion of high quantities of clove oil may cause serious diseases such as coma, coagulopathy and hepatic failure among others. ${ }^{48,49}$

\subsection{Applications}

Cloves have been used as a spice as well as for fragrance production in China for over 2000 years. $^{36}$ Eugenol possesses a characteristic and strong smell, with an odor threshold of 0.2-0.3 ng/L of air. ${ }^{50}$ In addition, in the traditional Chinese medicine, clove oil and buds are used as antimicrobial, antispasmodic, antiparasitic and to treat excessive intestinal gases, dyspepsia, gastritis and diarrhea. ${ }^{33,36}$ In Europe, it has been used to treat the toothache since at least the $17^{\text {th }}$ century. ${ }^{51}$ Eugenol possesses several pharmaceutical properties such as antioxidant, ${ }^{52,53}$ antibacterial, $^{54,55}$ antifungal, $^{56,57}$ antiparasitic, $^{33,34}$ antiviral, $^{58,59}$ anti-inflammatory, ${ }^{52,60}$ analgesic, ${ }^{60,61}$ and anticancer activity, $^{62,63}$ among many other properties. ${ }^{30}$ It is also reported to have anesthetic activity in fishes. ${ }^{64-66}$ Additionally, eugenol is widely used in cosmetics, perfumes, as 
well as a flavoring agent. Furthermore, it is possible to find eugenol as an ingredient in mouthwashes and in pharmaceutical and dental preparations, as well as in dentistry applications as a solid composite in combination with zinc oxide. ${ }^{33}$ Eugenol derivatives also possess various pharmacological properties such as antioxidant and antibacterial properties. $^{67,68}$ Thus, the functionalization of eugenol and the incorporation of eugenol-based monomers into macromolecular chains leads to polymers with additional interesting properties and therefore with potential applications in many fields.

\section{EUGENOL - REACTIVITY and FUNCTIONALIZATION}

\subsection{Eugenol reactive centers}

Eugenol, or 4-allyl-2-methoxyphenol, is a colorless to pale yellow oily liquid, soluble in organic solvents and slightly soluble in water $\left(2.463 \mathrm{~g} / \mathrm{L}\right.$ at $\left.25^{\circ} \mathrm{C}\right) .{ }^{69}, 70$ The chemical structure of eugenol, depicted in Scheme 1, was elucidated for the first time by Wassermann in $1875 .^{71}$ Eugenol possesses four main reaction sites: the phenolic hydroxyl group, the allyl group, the free positions of the aromatic ring and the methoxy group.

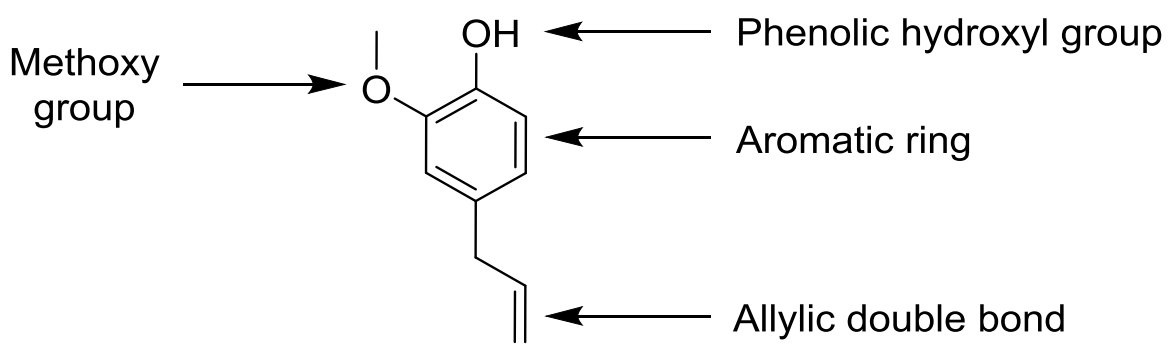

Scheme 1. Chemical structure of eugenol and its reaction sites.

Different possible reactions can be performed to functionalize eugenol to obtain eugenol-based monomers and polymers. Most of the (co)polymers containing eugenol moieties described in the literature are produced using eugenol-derived monomers where suitable functional groups were introduced to allow specific reactivity. For this reason, although there are many possible reactions to modify and to add new functional groups to eugenol for different purposes, the scope of this review will be to describe the most common and useful reactions to obtain eugenol-derived monomers. The selected reactions described in this review to functionalize eugenol on the four main reaction sites are summarized in Scheme 2. 


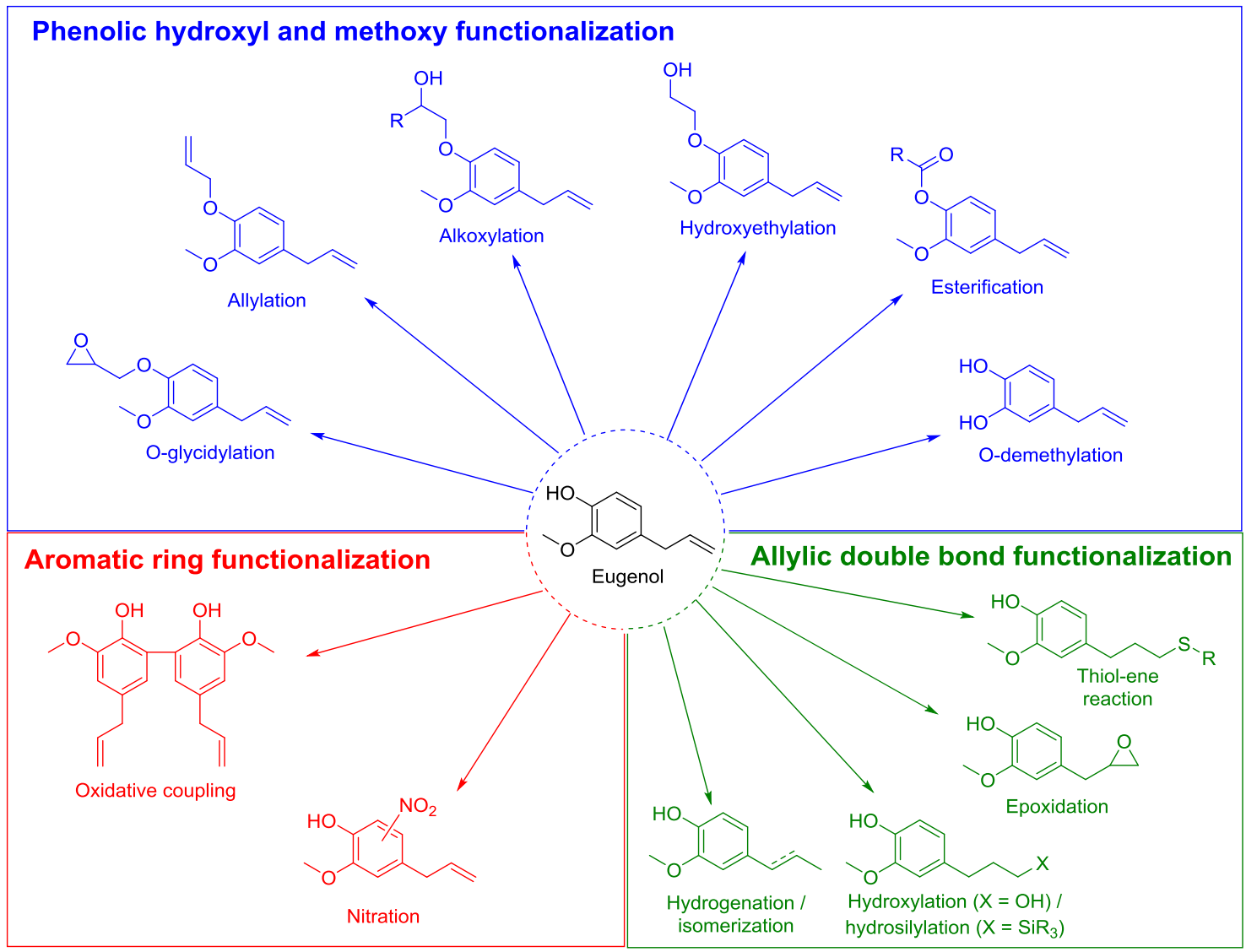

Scheme 2. Possible reactions to functionalize eugenol on its four main reaction sites.

\subsection{Allylic double bond functionalization}

\subsubsection{Thiol-ene reaction}

Thiol-ene "click" reaction, ${ }^{72}$ also called alkene hydrothiolation, is one of the most employed reactions to functionalize the allylic double bonds. This reaction enables the introduction of a wide range of functional groups in the eugenol allylic position through the addition of a thiol on the allylic double bond. Moreover, this reaction usually reaches high yields, and it is compatible with many functional groups, even under solvent-free conditions. Thus, it is widely used for the modification of polymers, thin-film fabrication, and dendrimer synthesis. ${ }^{73}$

They are many examples in the literature to introduce a large variety of functional groups by the thiol-ene coupling. The use of this reaction can lead to the functionalization of eugenol with an alkyl chain, ${ }^{74}$ a phenyl, ${ }^{75}$ a hydroxyl, ${ }^{76-78}$ an ester, ${ }^{76,79}$ a carboxylic acid, ${ }^{80}$ or a thiol group. ${ }^{81-83}$ The reaction can be carried out either thermally or photochemically, and with or without a radical initiator in both cases. Photochemical initiation requires UV irradiation, and it is generally carried out with a photoinitiator. Even if the use of a photoinitiatoir is not necessary, its utilization increases the reaction rate and the efficiency reducing the induction period. ${ }^{77} \mathrm{~A}$ typical 
synthetic procedure to perform the thiol-ene coupling consists of irradiating with UVA light $(\lambda=365 \mathrm{~nm})$ a mixture composed by eugenol and a thiol in the presence of 2,2dimethoxy-2-phenylacetophenone (DMPA) as depicted in Scheme 3 (a). ${ }^{74,76,84}$ However, the use of other radical photoinitiators, such as 2-hydroxy-2methylpropiophenone, can also be found in the literature. ${ }^{77,78}$

a)<smiles>[R]SCCc1ccc(O)c(OCC(C)C)c1</smiles><smiles>C=CCc1ccc(O)c(OC)c1</smiles>

b)

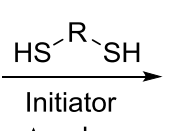<smiles>[R]CC(O)COC</smiles><smiles>CCOCCO</smiles><smiles>C=CCc1ccc(OC)c(OC)c1</smiles>
$\mathrm{R}=\mathrm{H}, \mathrm{OH}$

iii)<smiles>CC(C)(O)C(=O)c1ccccc1</smiles>

$\mathrm{h} v(365 \mathrm{~nm})$

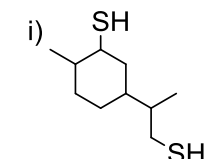

ii) $\mathrm{AIBN}$ $60^{\circ} \mathrm{C}$<smiles>[R]CC(O)COc1ccc(CCCSCC(C)C2CCC(C)C(SCCCc3ccc(OCC(O)C[R])c(OC)c3)C2)cc1OC</smiles>

Scheme 3. Thiol-ene reactions with eugenol and eugenol-derivatives.

On the other hand, thermal initiation can be carried out with a radical initiator such as azobisisobutyronitrile (AIBN). However, the use of an initiator is not always necessary and sometimes the reaction can be performed by simple heating depending on the activation energy of the reaction between the alkene and the thiol. For instance, Lenardão et $a l^{75}$ reported a method to functionalize eugenol with various aromatic thiols by thiol-ene coupling without any initiator and using glycerol as solvent. After 6 hours at $80{ }^{\circ} \mathrm{C}$, moderate yields (57-67\%) of thiol-ene coupling products were obtained, leading to various eugenol-based molecules with interesting antioxidant properties. Additionally, they observed that the ratio of the anti-Markovnikov and Markovnikov adducts depended on the substitution of the thiol aromatic ring. In practice, the coupling occurred in the anti-Markovnikov and Markovnikov position in ratios 78:22, 97:3 and 96:4 for benzenethiol, 4-chlorobenzenethiol and 3methylbenzenethiol, respectively. This behavior was attributed to the steric hindrance of the bulky groups. Additionally, the use of a dithiol allows to link two eugenol molecules by a dithiol as spacer as displayed in Scheme 3 (b). 
Montagut et al. $^{83}$ published the coupling of eugenol with an alkyl di-thiol (dodecane1,12-dithiol) in similar conditions, obtaining a significant yield (85\%) despite not using any initiator. There are also examples of the coupling of two eugenol-derived molecules through the allylic double bond using thiol-ene chemistry. For instance, Shrestra et al. ${ }^{85}$ published the dimerization of two alkoxylated eugenol derivatives with limonene dimercaptan to obtain biobased aromatic-aliphatic polyols as depicted in Scheme 3 (c). They performed the thiol-ene coupling by both thermal and photochemical initiation, using AIBN and 2-hydroxy-2-methyl propiophenone as radical thermal-initiator and photoinitiator, respectively. Concerning the reagent conversion, the obtained results suggested that thermal initiation is as effective as photochemical initiation and both initiation techniques provided polyols with similar properties.

Other examples of the synthesis of polyols for the preparation of different polymeric materials have been published. Some of them will be presented in the eugenol-derived polymer section (vide infra).

\subsubsection{Epoxidation}

Epoxidation of the allyl group of eugenol is usually carried out with metachloroperoxybenzoic acid ( $m$-CPBA) as shown in Scheme $4 .{ }^{86-88}$ Generally, this reaction is performed after prior protection or after a previous functionalization of the phenolic hydroxyl group. Otherwise, phenolic group may react with $m$-CPBA generating byproducts. The protection can be achieved with acetic anhydride $\left(\mathrm{Ac}_{2} \mathrm{O}\right)^{89}$ or with silyl groups ${ }^{90}$ among other phenolic protecting groups. Note that silanes also react with the methoxide group of eugenol and thus the subsequent deprotection leads to a catechol group as detailed in Section 3.4.2. However, this kind of protection can be useful since other protecting groups may be cleaved or react during successive chemical transformations. ${ }^{90}$ Epoxidation on the allylic double bond could also be done using Oxone $^{\circledR}$ (potassium peroxymonosulfate) and a mixture of water and acetone as solvents. ${ }^{91}$ The use of Oxone ${ }^{\circledR}$ instead of $m$-CPBA is a greener alternative since Oxone ${ }^{\circledR}$ is not a chlorinated oxidizing agent and atom economy is improved.

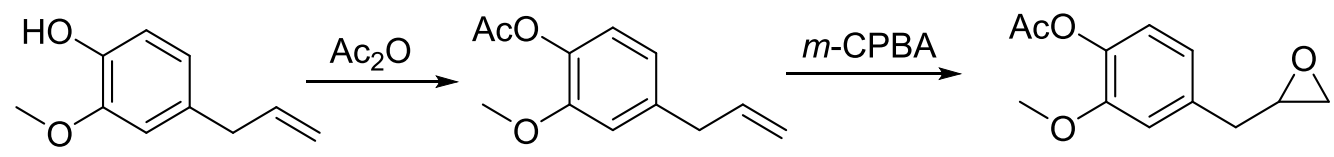

Scheme 4. Epoxidation of allyl group of eugenol.

\subsubsection{Hydroxylation}

Hydroxylation of the allyl group of eugenol allows to obtain primary or secondary alcohols. This reaction is usually performed by hydroboration-oxidation of eugenol (Scheme 5). ${ }^{92-95}$ 


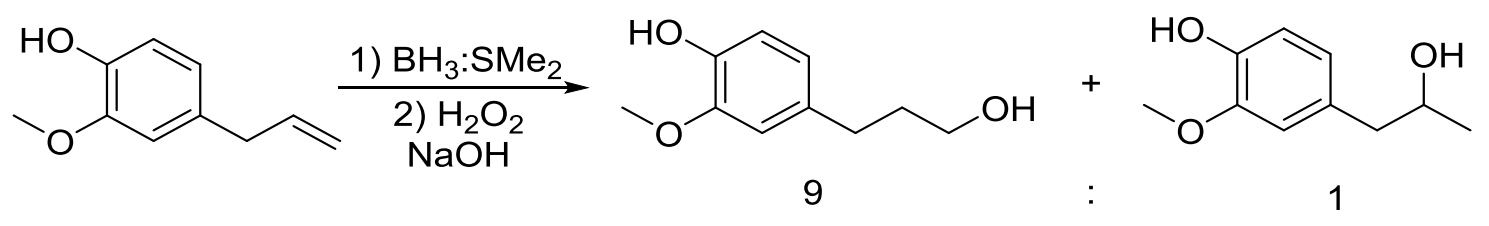

Scheme 5. Hydroboration-oxidation of eugenol.

However, although hydroboration-oxidation is stereoselective (anti-Markovnikov), a small fraction of the Markovnikov adduct is also reported by these conditions (9:1). Thus, further purification by column chromatography is necessary to obtain the pure stereoisomer. The use of a bulkier hydroborating agent such as 9borabicyclo(3.3.1)nonane (9-BBN), which should normally increase the stereoselectivity, does not lead to a higher rate of the expected stereoisomer. ${ }^{93}$ In fact, the global yield of the reaction drops considerably. ${ }^{92}$ On the other hand, the Markovnikov adduct can be obtained by an epoxidation of the alkene followed by a hydrogenation with $\mathrm{Pd}-\mathrm{C}$ in methanol. ${ }^{96}$

Dihydroxylation of eugenol results in a 1,2-diol compound, but this reaction requires a previous protection step of the phenolic group, which can be achieved with benzyl bromide. Then, protected eugenol can react with osmium tetroxide to yield a eugenolderived 1,2-diol. ${ }^{97,} 98$ The resulting compound can be deprotected (to eliminate the benzyl group) by hydrogenation. Alternatively, dihydroxylation of eugenol can be also achieved by the formation of the epoxide followed by a treatment with an aqueous solution of sulfuric acid, avoiding the use of the extremely toxic osmium tetroxide. ${ }^{96}$

\subsubsection{Hydrosilylation}

Hydrosilylation of eugenol consists in the reaction between $\mathrm{Si}-\mathrm{H}$ bonds and the allyl group of eugenol and yields a eugenol-based alkyl silane. This reaction is usually catalyzed by organoplatinum compounds, such as chloroplatinic acid, ${ }^{99,} 100$ tetrakis(triphenylphosphine)palladium(0), ${ }^{101}$ or Karstedt's catalyst. ${ }^{102}$ Functionalization of polysiloxanes with eugenol yields polysiloxanes with remarkable anticorrosion properties. Moreover, the presence of a eugenol moiety confers antibacterial properties to silicone resins, which thus can be used for biomedical applications. ${ }^{100}$ Additionally, the thermal stability of these resins is improved due to the presence of the aromatic ring of eugenol.

\subsubsection{Olefin methathesis}

Olefin metathesis and olefin cross-metathesis ${ }^{103}$ are powerful techniques to generate new $\mathrm{C}-\mathrm{C}$ bonds, offering a wide range of possibilities to functionalize, isomerize, dimerize or polymerize eugenol and eugenol-derivatives. An illustrative example of eugenol functionalization by olefin cross-metathesis has been described by Taber and 
Frankowski. ${ }^{104}$ In this work, eugenol reacts with cis-2-butene-1,4-diol in the presence of a Grubbs' second-generation catalyst, resulting in (E)-4-(4-hydroxybut-2-en-1-yl)-2methoxyphenol as shown in Scheme 6 (a).

Dimerization and isomerization of eugenol is another interesting reaction which can be carried out by olefin self-metathesis as described by Brett Runge et al. ${ }^{105}$ Indeed, dimerization of eugenol derivatives is an interesting tool to obtain difunctionalized monomers by olefin self-metathesis using either the first or second generation Grubbs' catalyst or Hoveyda-Grubbs catalysts. ${ }^{106,107}$ Subsequent hydrogenation of the double bond results in a eugenol-dimer (bisphenol), which can subsequently be functionalized through the hydroxyl group. Another interesting example is the synthesis of a diepoxy eugenol-based monomer, which can be a substitute to bisphenol A diglycidyl ether (DGEBA). It was reported by the self-metathesis of eugenol glycidyl ether (EGE) with a second generation Grubbs' catalyst as depicted in Scheme 6 (b). ${ }^{108}$

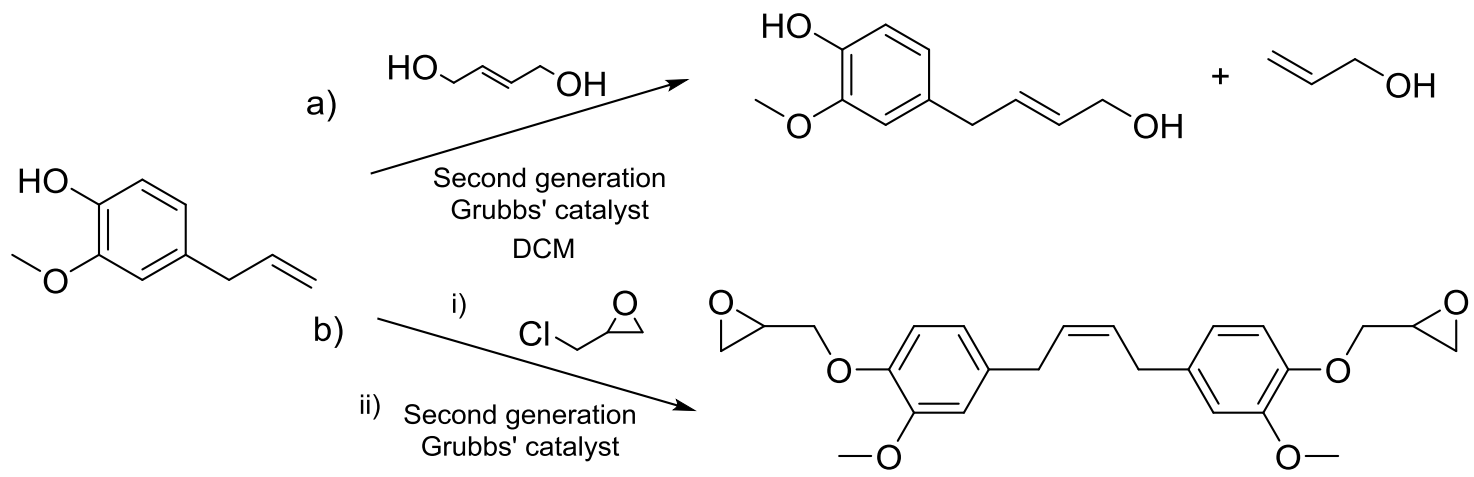

Scheme 6. (a) Olefin cross-metathesis and (b) self-metathesis of eugenol-derivatives with second generation Grubbs' catalyst.

\subsubsection{Hydrogenation}

The hydrogenation of the allylic double bond of the eugenol yields 2-methoxy-4propylphenol, which is a molecule that can be further functionalized through the phenol or aromatic ring. ${ }^{109}$ This has been found to be useful in radical polymerization reactions as it prevents the formation of highly stabilized radicals produced by chain transfer reactions on the allylic groups. Further examples will be presented in the polymers section of this review. It is important to mention that the hydrogenated form of eugenol can be obtained from the reductive depolymerization of lignin as well. ${ }^{23}$

\subsubsection{Isomerization}

Isomerization of the allylic double bond to form the propenyl group can be achieved by using a stoichiometric amount of a base under heating. ${ }^{110,111}$

\subsection{Phenol functionalization}




\subsubsection{Allylation}

Allylation of eugenol is a commonly employed reaction to functionalize the phenolic hydroxyl group with a supplementary allyl group. This reaction enables the introduction of two allyl functions, which can be employed to produce linear and cross-linked polymers by subsequent reactions such as thiol-ene or ene reaction, improving the thermal and mechanical properties. ${ }^{112}$ In addition, olefins are an interesting precursor of many other functions such as hydroxyl or epoxide groups, among others.

Allylation of eugenol is generally carried out by the Williamson ether synthesis. Neda et al. ${ }^{112}$ reported the synthesis of allyl-etherified eugenol (AEG) using allyl bromide and sodium hydroxide $(\mathrm{NaOH})$ in DMSO in high yield (96\%) as depicted in Scheme 7. This synthetic strategy has been followed by several authors to obtain AEG. ${ }^{113-118}$ Other solvents such as acetone or DMF can be used in this synthesis producing similar yields. ${ }^{91,119}$ The reaction can be performed with potassium carbonate $\left(\mathrm{K}_{2} \mathrm{CO}_{3}\right)$ as the base instead of $\mathrm{NaOH},{ }^{120,121}$ leading also to high reaction yields. ${ }^{122,}{ }^{123}$ However, anhydrous DMF was used as solvent, which is considered a harmful solvent, whereas the use of other solvents such as acetone caused a significatively drop in the reaction yield (56\%). ${ }^{124}$

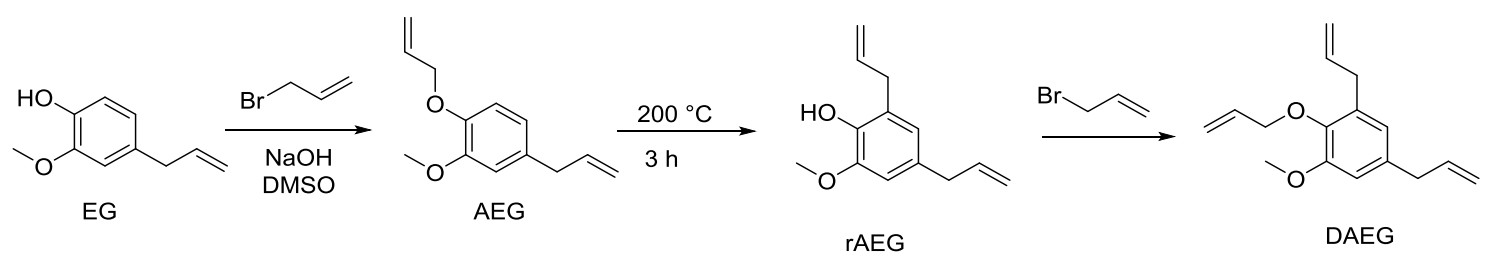

Scheme 7. Allylation of eugenol by the conditions proposed by Neda et $a l^{112}$ and aromatic-Claisen rearrangement of AEG and allylation of $\mathrm{rAEG}$.

A different synthetic pathway to obtain AEG was published by Llevot et al.., ${ }^{125}$ which employed the Tsuji-Trost allylation. ${ }^{126,127}$ In this case, eugenol reacts with allyl methyl carbonate in the presence of triphenylphosphine and palladium nanoparticles stabilized by poly(vinylpyrrolidone) as catalyst. The reaction was carried out in water as solvent, resulting in $85 \%$ yield. AEG can also be obtained by the reaction of eugenol with allyl alcohol in the presence of diisopropyl azodicarboxylate and triphenyl phosphine in THF, resulting in $71 \%$ yield. ${ }^{128}$

Interestingly, an aromatic-Claisen rearrangement occurs on AEG under pyrolytic conditions, yielding 2,4-diallyl-6-methoxyphenol ( $\mathrm{rAEG}),{ }^{112,} 115,117$ which can be etherified again with allyl bromide yielding a tri-allyl compound (1,3-diallyl-4-allyloxy5-methoxybenzene or DAEG) as depicted in Scheme $7 .{ }^{114}$ 


\subsubsection{O-glycidylation}

O-glycidylation of the phenolic hydroxyl group of eugenol yields EGE by a Williamson ether synthesis mechanism. This reaction is typically performed with epichlorohydrin in the presence of sodium hydroxide. ${ }^{108,129-133}$ It can be carried out in bulk or with a solvent such as ethanol or 2-propanol. It is noteworthy that quite different yields are observed in the literature, depending on the experimental procedure, going from $65 \%$ to over than $90 \%$ yield. The use of benzyltriethylammonium chloride (BETAC) ${ }^{108,130}$ or tetra- $n$-butylammonium bromide $(\mathrm{TBAB})^{131}$ as phase transfer catalysts is also considered by several authors. O-glycidylation uses epichlorohydrin as reagent, which is classified as a toxic and carcinogenic substance, and it is generally obtained from fossil resources. Nevertheless, biobased epichlorohydrin, produced from glycerol is commercially available (Epicerol ${ }^{\circledR}$ from Solvay). ${ }^{108}$

Functionalization of both positions by sequential epoxidation and O-glycidylation must be performed in this specific order as shown in Scheme 8. It is important to perfrom epoxidation of the allyl group after a previous protection of the phenolic function and then to carry out the O-glycidylation. Otherwise, the reaction yields a complex brown mixture that is difficult to purify. ${ }^{89}$ Additionally, O-glycidylation can be done directly on the acetylated eugenol without the deprotection step. However, the O-glycidylation yield drops significantly (63\%) compared to the O-glycidylation of a non-protected hydroxyl group using similar conditions.

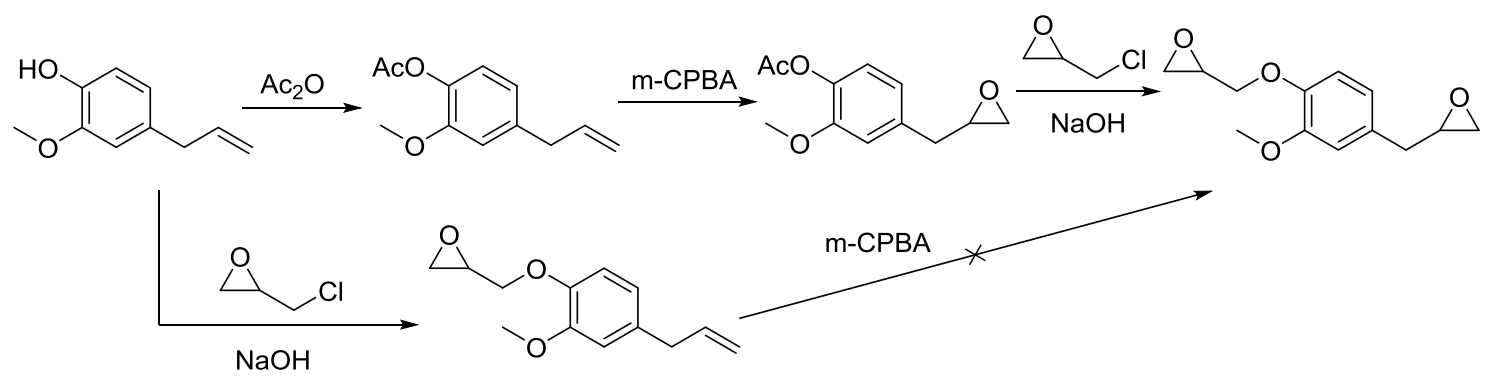

Scheme 8. Sequential epoxidation and O-glycidylation of eugenol. ${ }^{89}$

Eugenol di-epoxide can also be obtained by allylation of the phenolic hydroxyl position followed by epoxidation of both allyl groups as shown by Guzman et al., ${ }^{91}$ which employed this method but using Oxone ${ }^{\circledR}$ instead of $m$-CPBA as oxidizing agent.

\subsubsection{Alkoxylation}

Alkoxylation of eugenol consists of the reaction of the phenolic hydroxyl group with an epoxide, provoking the ring-opening of the epoxide and leading to a hydroxyl group. For instance, Shrestha et al. $^{85}$ synthesized propoxylated eugenol with by the 
alkoxylation of eugenol with an excess of propylene oxide (Scheme 9). The reaction was carried out in an autoclave using 1,1,3,3-tetramethylguanidine (TMG) as catalyst, obtaining a quantitative yield. The autoclave had to be cooled to control the temperature and the pressure since the reaction is highly exothermic. Additionally, the authors described the synthesis a 1,2-diol compound derivative from eugenol by this method but using glycidol instead of propylene oxide as depicted in Scheme 9. Both synthesized compounds were subsequently dimerized by the thiol-ene reaction, resulting in biobased polyols which can be used for the synthesis of polyurethanes.

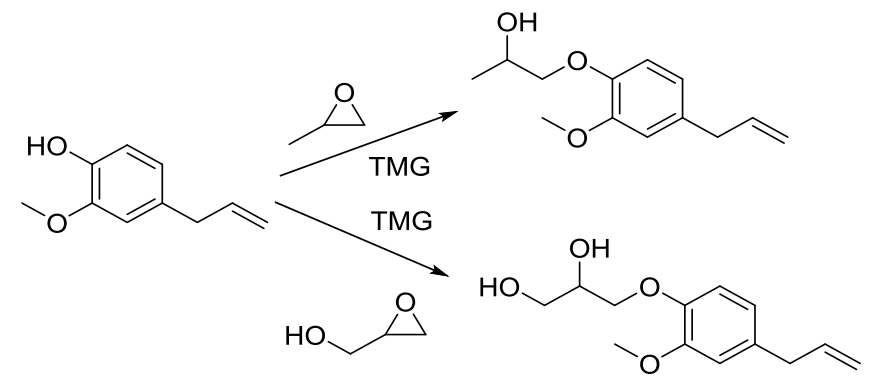

Scheme 9. Alkoxylation of eugenol with propylene oxide and glycidol.

\subsubsection{Hydroxyethylation}

Hydroxylation of eugenol involves the introduction of a hydroxyethyl group in the phenolic hydroxyl group to form 2-eugenyl ethanol. Rojo et al. ${ }^{134}$ achieved the synthesis of 2-eugenyl ethanol by a Williamson ether synthesis using eugenol and 2chloroethanol in the presence of potassium hydroxide as a base and potassium iodide as co-catalyst. However, a greener synthesis, to avoid the toxic and harmful halogenated reagents, can be carried out by the use of ethylene carbonate instead of 2-chloroethanol. ${ }^{76}$ Additionally, the use of 1,5-diazabicyclo(4.3.0)non-5-ene (DBN) as catalyst with higher temperatures and without solvent led to the same product in higher yield. ${ }^{135,136}$ Hydroxyethylation by both techniques, using 2-chloroethanol and using ethylene carbonate, is depicted in Scheme 10.

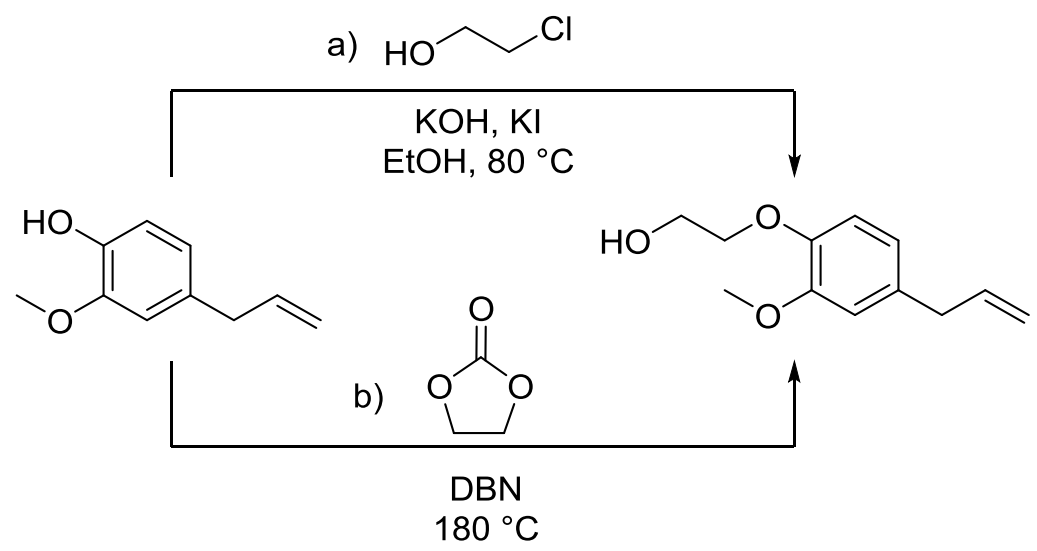

Scheme 10. Synthesis of 2-eugenyl ethanol with a) 2-chloroethanol and b) ethylene carbonate. 


\subsubsection{Esterification}

Phenolic hydroxyl group of eugenol can be esterified to introduce an alkyl chain. For instance, it is possible to form eugenyl acetate easily by the reaction of eugenol with acetic anhydride. ${ }^{137}$ However, in this section we will focus on the esterification reaction to introduce an acrylate or methacrylate function, since these functions can be polymerized. Acrylic and methacrylic monomers are widely used in the industry because of their low cost, ease of production and the properties of the corresponding polymers such as their relatively high thermal stability as well as a high resistance to breakage.

The introduction of a methacrylic group allows the radical polymerization of eugenol, which does not promptly occur through the allyl group and also suffers from the radical scavenging character of the phenol group. ${ }^{138}$ Rojo et al. ${ }^{134}$ published the methacrylation reaction of eugenol and 2-eugenyl ethanol leading to eugenol-based methacrylated monomers in order to obtain (co)polymers by conventional radical polymerization for applications in dental composites and as orthopedic bones cements. The methacrylation of eugenol was carried out with methacryloyl chloride, which can react directly with phenolic group to form 4-allyl-2-methoxyphenyl methacrylate. On the other hand, 2-(4-allyl-2-methoxyphenoxy)ethyl methacrylate, with a spacer group between the methacrylic and the eugenol moieties, was obtained by hydroxyethylation followed by the reaction with methacryloyl chloride. ${ }^{134,}{ }^{139}$ The introduction of a spacer reduces the risk of hydrolysis of the ester group ${ }^{135}$ and provides a higher steric freedom which influences the bioactivity. ${ }^{139}$ Both reactions are displayed in Scheme 11. As mentioned before, it is possible to synthesize 2-eugenyl ethanol without the use of halogenated reagents by using cyclocarbonates. ${ }^{135,136}$ Then, methacrylation can be performed by using methacrylic anhydride and triethylamine.

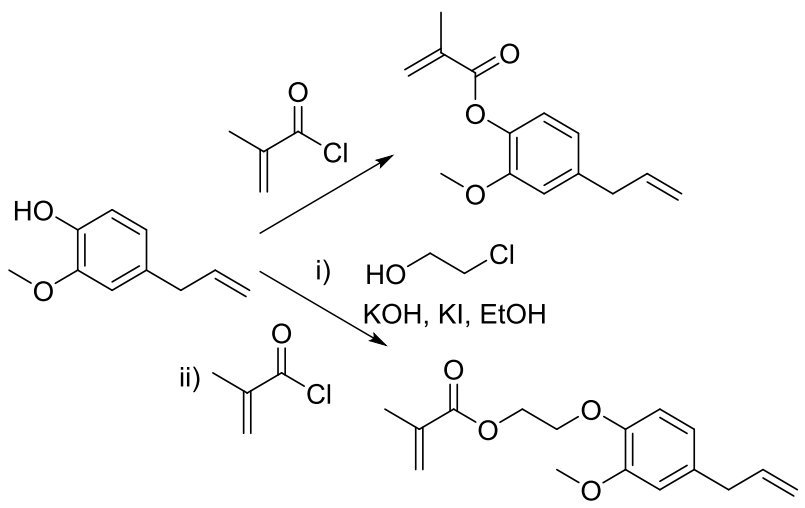

Scheme 11. Synthesis of i) 4-allyl-2-methoxyphenyl methacrylate and ii) 2-(4-allyl-2methoxyphenoxy)ethyl methacrylate from eugenol. 
The introduction of an acrylic group instead of a methacrylic group with and without a spacer by a similar procedure was also reported. ${ }^{140}$ Reaction of the phenolic group with acrylic acid in the presence of $N, N^{\prime}$-dicyclohexylcarbodiimide (DCC) and 4dimethylaminopyridine (DMAP) as catalyst led to the acrylated eugenol but in moderate yields ( $68 \%$ yield). ${ }^{141}$

Eugenol-based monomers containing two acrylate functions in order to obtain crosslinked networks have been also reported. The dimerization of eugenol with a dithiol by thiol-ene reaction yields a diphenol, which can be then acrylated with acryloyl chloride. ${ }^{142}$ Additionally, the introduction of a methacrylate group in both phenolic hydroxyl and allylic double bond was also reported by Dai et al. ${ }^{80}$ The strategy to synthesize the eugenol-derived methacrylates monomers consisted in the introduction of a mono- or di-acid in the allylic double bond by thiol-ene reaction. Then, glycidyl methacrylate reacted with the carboxylic acid group and the phenolic group in the presence of tetra- $n$-butylammonium bromide (TBAB) yielding di- or tri-functionalized eugenol-based methacrylates. These monomers were copolymerized using UV irradiation with acrylated eugenol and acrylated epoxidized soybean monomers.

\subsection{Methoxy group}

\subsubsection{O-demethylation}

O-methyl group of eugenol can be converted to a hydroxyl function leading to a cathecolic group. This reaction can be carried out by oxidative O-demethylation using 2-iodoxybenzoic acid (IBX) or stabilized 2-iodoxybenzoic acid (SIBX) as depicted in Scheme 12 (a). 4-Allylpyrocatechol was obtained in both cases in moderate yields (67\% and $77 \%$, respectively). ${ }^{143} \mathrm{~A}$ quantitative yield (99\%) can be reached using aluminum iodide with an excess of pyridine in acetonitrile ${ }^{144}$ or aluminum chloride with 1,3diisopropylcarbodiimide (DIC) and an excess of sodium iodide. ${ }^{145}$

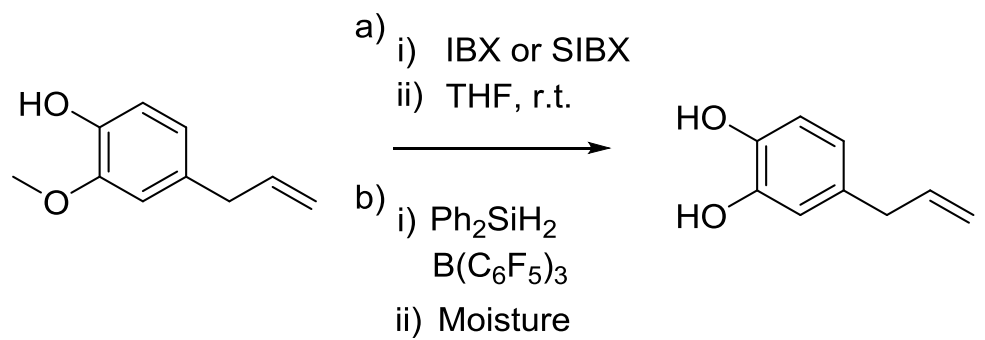

Scheme 12. Oxidative O-demethylation of eugenol. ${ }^{90,143}$ 


\subsubsection{Silylation and O-demethylation}

Methoxy group of eugenol, as well as the hydroxyl phenolic group, can react with silanes. ${ }^{90}$ The reaction can be carried out with diphenylsilane, a silyl protecting group, in presence of tris-(pentafluorophenyl)borane as displayed in Scheme 12 (b). The silane reacts with both the methoxy and the phenolic hydroxyl group. The resulting compound is extremely moisture sensitive. The authors indeed realized that the compound reacted during the silica gel column chromatography to yield 4allylpyrocathecol quantitatively, reaching $77 \%$ of global reaction yield.

\subsection{Aromatic ring functionalization}

\subsubsection{Nitration}

Nitroeugenol allows to obtain eugenol derivatives with interesting functional groups such as amine (aniline), which can be a precursor of novel attractive molecules and thus interesting polymers, some of them possessing bioactive properties. ${ }^{146-150}$ Nitration of eugenol was reported since the nineteenth century by Weselsky et al. ${ }^{151}$ carried out with fuming nitric acid for $24 \mathrm{~h}$, followed by a treatment with potassium hydroxide. After further purification, elemental analysis matched with the expected values of nitroeugenol. The molecular structure of eugenol was described short time before, ${ }^{71}$ and it was concluded that the obtained product should be ortho-nitroeugenol (4-allyl-2-methoxy-6-nitrophenol), since the para position is already occupied. A high reaction yield (up to 79\%) of ortho-nitroeugenol can be obtained performing the reaction with nitric acid (70\%) in acetic acid. ${ }^{152}$ More recently, Sudarma et al. ${ }^{153}$ analyzed several methods to obtained ortho-nitroeugenol, concluding that the best conditions to carry out this reaction is using a mixture of ammonium nitrate and potassium bisulfate in acetonitrile (Scheme 13 ), reaching $86 \%$ yield.

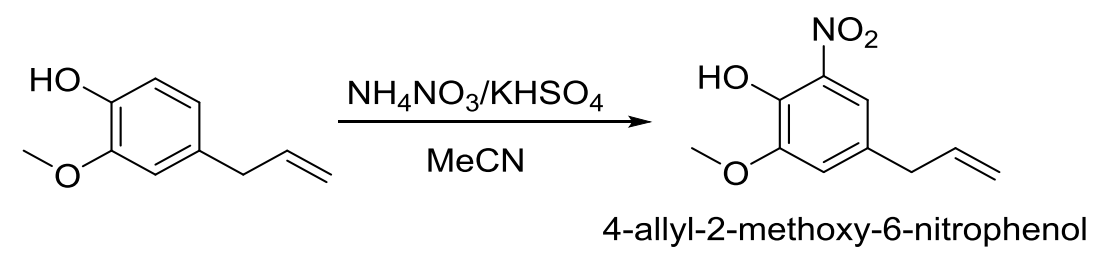

Scheme 13. Synthetic pathway to obtain ortho-eugenol proposed by Sudarma et al. ${ }^{153}$

The synthesis of meta-nitroeugenol (4-allyl-2-methoxy-5-nitrophenol) was reported for the first time by Clemo et al. ${ }^{154}$ in 1949 . The synthetic pathway starts from eugenyl acetate which reacts with a mixture of nitric acid and acetic anhydride. On the other hand, the synthesis of 4-allyl-2-methoxy-3-nitrophenol can be achieved by the protection of the phenolic group with an acetyl group followed by the reaction with 
nitrating mixture $\left(\mathrm{HNO}_{3}\right.$ and $\mathrm{H}_{2} \mathrm{SO}_{4}$ 1:1) in dichloromethane. ${ }^{155}$ In fact, this reaction yields both nitrated products in meta position, 4-allyl-2-methoxy-3-nitrophenol and 4allyl-2-methoxy-5-nitrophenol. After separation of the two isomers by column chromatography (petroleum ether/ethyl acetate mixtures increasing polarity), the deprotection of the acetyl group was carried out with potassium carbonate in methanol. Additionally, this paper reported the antifungal activities of nitroeugenol and nitroeugenol-derivatives, which were compared according to the position of the nitro group. The best antifungal activity was obtained for ortho-nitroeugenol (allyl-2methoxy-6-nitrophenol).

\subsubsection{Oxidative coupling}

Oxidative coupling allows to dimerize eugenol through the formation of a C-C linkage between the aromatic group of two eugenols in ortho position of phenolic hydroxyl group to obtain dehydrodieugenol. Dimerization of eugenol by oxidative coupling allows to obtain a eugenol dimer while maintaining the two main reactive sites of eugenol (phenolic hydroxyl group and allylic double bond group). Dehydrodieugenol has been obtained since the beginning of the twenteenth century by the reaction of eugenol with ferric chloride $\left(\mathrm{FeCl}_{3}\right)$ or even by the oxidation of eugenol with ferments of mushroom (Russula delica). ${ }^{156}$ Later, dehydrodieugenol was obtained by De Farias Dias $^{157}$ in almost quantitative yield (98\%) using potassium ferricyanide $\left(\mathrm{K}_{3} \mathrm{Fe}(\mathrm{CN})_{6}\right)$ dissolved in a mixture of acetone and ammonium hydroxide, followed by a treatment with hydrochloric acid as depicted in Scheme 14. This synthetic pathway has been employed by several authors to obtain dehydrodieugenol for the synthesis of bismaleimide (BMI) resins, ${ }^{158}$ for allyl and epoxy functionalization to use in thiol-ene or thiol-epoxy reaction, ${ }^{91}$ or to obtain diols by hydroxyethylation for PU synthesis. ${ }^{159}$ Additionally, dehydrodieugenol exhibited remarkable antioxidant properties (even higher than eugenol and other eugenol derivatives) ${ }^{67}$ and antibacterial properties, ${ }^{160}$ as well as a lower cytotoxicity than eugenol. ${ }^{161}$ Thus, dehydrodieugenol has potential biomedical applications, especially in dentistry for the synthesis of zinc oxide eugenol cements. $^{161}$

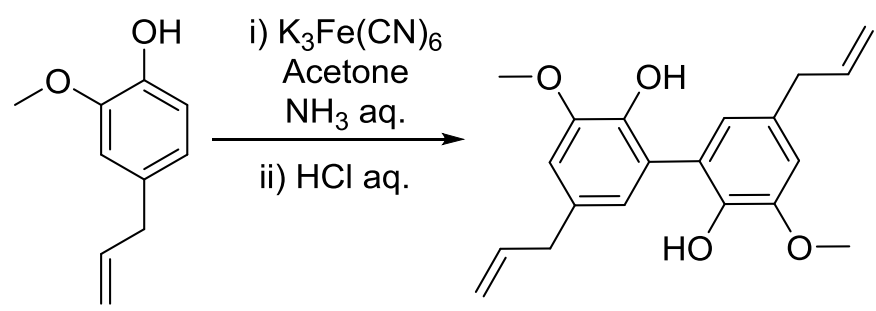

Scheme 14. Oxidative coupling of eugenol with $\mathrm{K}_{3} \mathrm{Fe}(\mathrm{CN})_{6}$.

Alternative syntheses of dehydrodieugenol were published later using methyltributylammonium permanganate ${ }^{162}$ or iron(II) sulfate with hydrogen 
peroxide, ${ }^{160}$ but all of them with lower reaction yields. Later, a greener synthesis using hydrogen peroxide with an enzymatic catalyst (horseradish peroxidase) was reported, increasing considerably the reaction yield to $94 \%{ }^{163}$ Enzymatic catalysis was also employed by Llevot et al. ${ }^{164}$ to obtain dehydrodieugenol in high yields (87\%), using laccase from Trametes versicolor as catalyst. Additionally, dehydrodieugenol can be obtained by electrochemical dehydrodimerization using reusable carbon-based electrodes reaching $80 \%$ yield. ${ }^{165}$

The chemical structure of eugenol with its four main reactive sites (allylic double bond, aromatic ring, methoxy group, and phenolic hydroxyl group) allows introducing a wide variety of functional groups that can be used in the synthesis of novel materials with interesting properties and aiming different applications. Nowadays, biobased polymeric materials are of high interest as it is a priority to substitute their petroleumbased counterparts in the pursuit of a more sustainable chemistry. In the next section, several examples of eugenol-derived monomers used to obtain different types of polymers are provided.

\section{EUGENOL-BASED POLYMERS}

Taking advantage of the wide variety of functionalization reactions on the eugenol chemical structure, different monomers can be obtained. This platform of monomers provides multiple possible polymerization reactions to produce new materials. In the following section, some examples of polymerization reactions through different mechanisms are selected and presented.

\subsection{Step growth polymerization}

\subsubsection{Polyurethanes}

Polyurethanes represent around $6 \%$ of the total polymer market ${ }^{166}$ with applications in paints, coatings, elastomers, insulators, elastic fibers, foams and integral skins, among others. ${ }^{167}$ The introduction of biobased building blocks for the production of polyurethanes has been reported. ${ }^{168}$ Lignin is of particular interest as a feedstock due to the presence of hydroxyl and aromatic ring groups. Previous studies were done directly using lignin as a source of hydroxyl groups for the synthesis of polyurethanes. Nevertheless, disadvantages of using lignin were encountered related to solubility and reactivity issues. One of the possible solutions was to use the products of lignin depolymerization and their derivatives. ${ }^{166}$

Polyurethanes are polymers which contain urethane linkages. Usually, the urethane linkage is formed by the reaction of an isocyanate with a hydroxyl group. The use of a compound containing two or more isocyanate groups with a polyol lead to a polyurethane. Thus, there are two possibilities to synthesize eugenol-based polyurethanes: using a eugenol-based polyol or using a eugenol-based diisocyanate. There are several studies which employ eugenol-based polyols to obtain 
polyurethanes. However, to the best of our knowledge, eugenol-based isocyanates are not reported in the literature yet.

Eugenol-based polyols can be obtained through different synthetic pathways. An interesting strategy was published by Li et al., ${ }^{159}$ consisting in the formation of a eugenol dimer by oxidative coupling and then by the hydroxyethylation of the phenol groups, yielding di(hydroxyethyl) dieugenol. In this article, the urethane linkages were formed by the reaction of the di(hydroxyethyl)dehydrodieugenoleugenol with hexamethylene diisocyanate (HDI) as depicted in Scheme 15 . The resulting polyurethane was only characterized by FTIR spectroscopy, with a peak at $1740 \mathrm{~cm}^{-1}$ corresponding to the signal of the urethane bond.

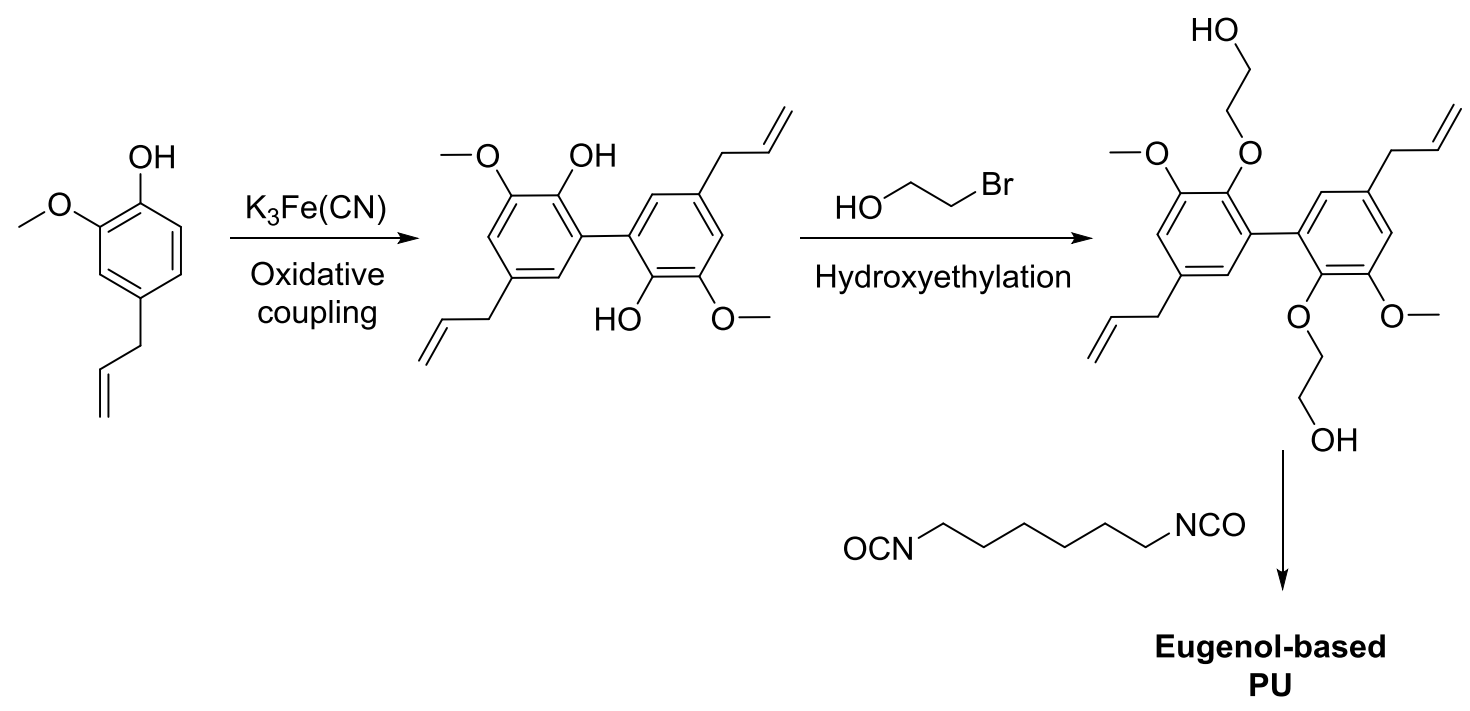

Scheme 15. Synthesis of a eugenol-based polyol by oxidative coupling and hydroxyethylation and subsequent eugenol-based polyurethane synthesis. ${ }^{159}$

Additionally, the phenolic hydroxyl group of eugenol can directly react with isocyanates to produce an urethane bond. ${ }^{169}$ Alternatively, eugenol-derived polyols can also be synthesized by introducing hydroxyl groups through the allylic double bond. Thiol-ene reaction was used to introduce hydroxyl groups, and consequently the resulting compounds can react with a diisocyanate to produce a polyurethane as shown in Scheme $16 .^{77}$ Resulting PUs exhibited glass transition temperatures between 36 and $77^{\circ} \mathrm{C}$ and good mechanical properties, particularly a high tensile strength (over 54.8 $\mathrm{MPa}$ ). Furthermore, polyols can be obtained from the coupling of two eugenol molecules using a dithiol as exemplified in the thiol-ene section (vide supra). Shrestra et al., ${ }^{85}$ prepared partially biobased rigid polyurethane foams (PUF) from the polyol derived from limonene mercaptan and alkoxylated eugenol as depicted in Scheme 16. Resulting aliphatic-aromatic PUFs showed superior mechanical properties compare to PUFs based exclusively on biobased aliphatic polyols. The authors claimed a wide 
variety of possible applications of these materials such as thermal insulation, food industries, packaging, and flotation materials.

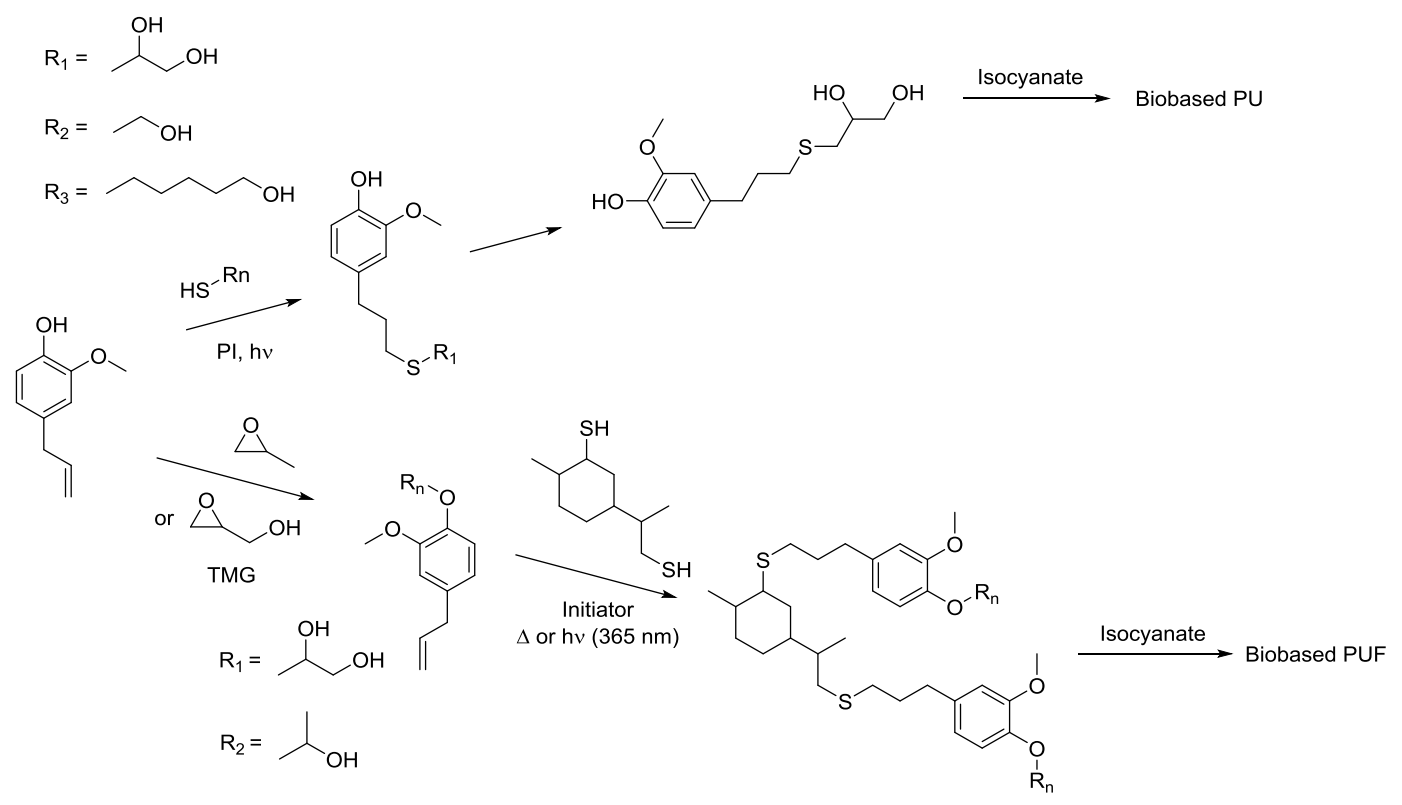

Scheme 16. Synthesis of polyols using thiol-ene reaction to produce polyurethanes.

An example of eugenol-derived polymer through thiol-ene polymerization was prepared from a monomer obtained from a series of reactions involving the condensation reaction between eugenol and eugenol glycidyl ether by thiol-ene, yielding a diallyl monomer with a spacer containing a secondary hydroxyl group (Scheme 17).

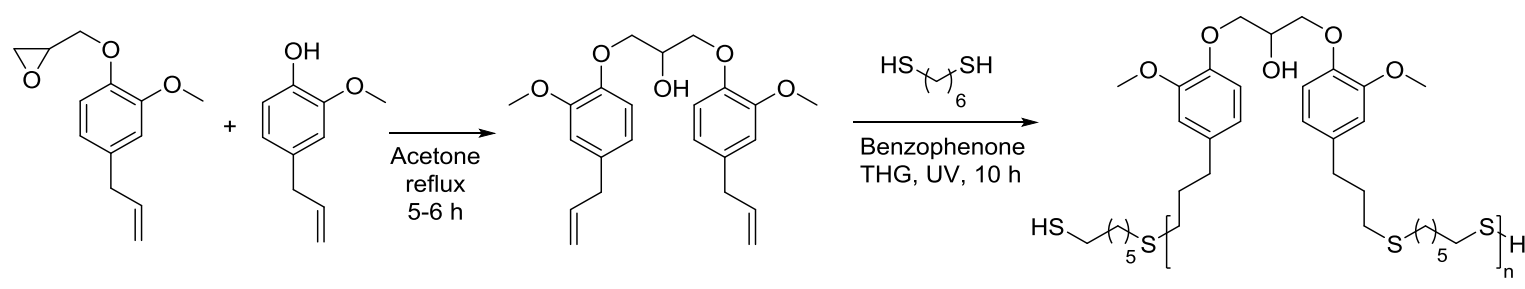

Scheme 17. Eugenol-derivative thiol-ene polymerization.

This prepolymer was further reacted through thiol-oxidation (with itself and with other thiols) and then cured (through the free hydroxyl groups) with a diisocyanate such as hexamethylene diisocyanate (HDI) to obtain a materials with self-healing performance under UV irradiation, coming from the dynamic disulfide bonds and hydrogen bonds in the polymers. ${ }^{170}$

Non-isocyanate polyurethanes (NIPUs) ${ }^{171,}{ }^{172}$ are polymers containing urethane linkages which have been synthesized without the use of the toxic and harmful 
isocyanates. There are many ways to obtain NIPUs, but one of the most used is the reaction of a cyclic carbonate with an amine. Cheng et al. ${ }^{89}$ reported the synthesis of a eugenol-based dicyclic carbonate starting from the diepoxy eugenol. This monomer was able to react with a diamine (4,4'-diamino diphenylmethane) (Scheme 18). This reaction was also used to cure an eugenol-based siloxane bearing a cyclic carbonate. ${ }^{131}$

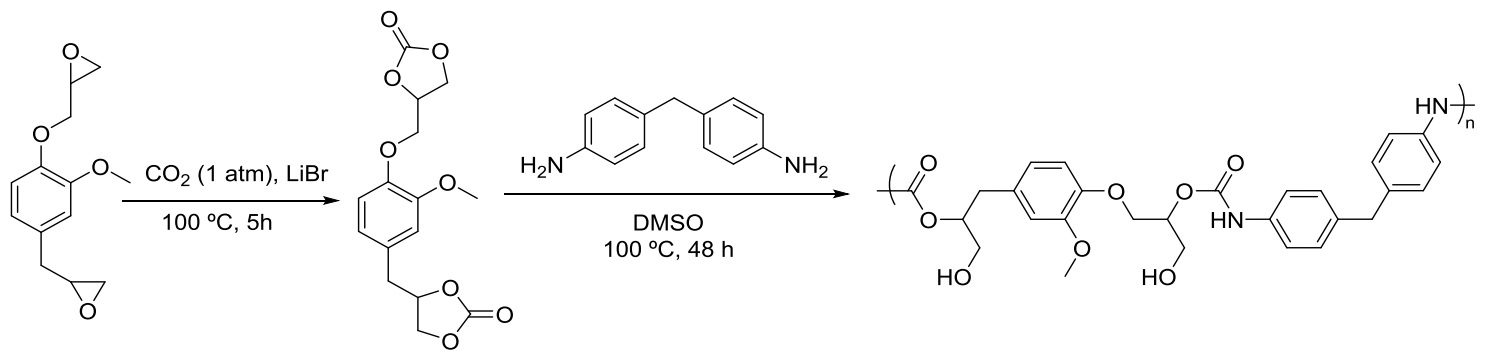

Scheme 18. Synthesis of eugenol-derived carbonates to produce non-isocyanate polyurethanes.

\subsubsection{Thiol-oxidation}

Thiol oxidation is the reaction of two thiol groups to lead a disulfide group. The reaction is carried out in the presence of an oxidant, generally hydrogen peroxide. This reaction allows to obtain linear polymers with a dithiol, or cross-linked polymers when employing tri- or tetra-thiols. As described previously, eugenol and eugenol derivatives can be functionalized with thiol groups by thiol-ene reaction with a dithiol, as depicted in Scheme 19. The dithiol eugenol derivatives can be then polymerized using thioloxidation. This strategy was followed by Cheng et al. ${ }^{124,173}$, who prepared linear eugenol-based polymers from allyl eugenol and hexanedithiol. The resulting polymers possess thiol function in chain-ends, allowing the subsequent polymerization by thioloxidation with themselves or the cross-linking with trithiols such as trimethylolpropane tris(3-mercaptopropionate). Resulting cross-linked polymers showed good mechanical properties, reaching a tensile strength value about $6 \mathrm{MPa}$ and an elongation at break of around $300 \%{ }^{173}$

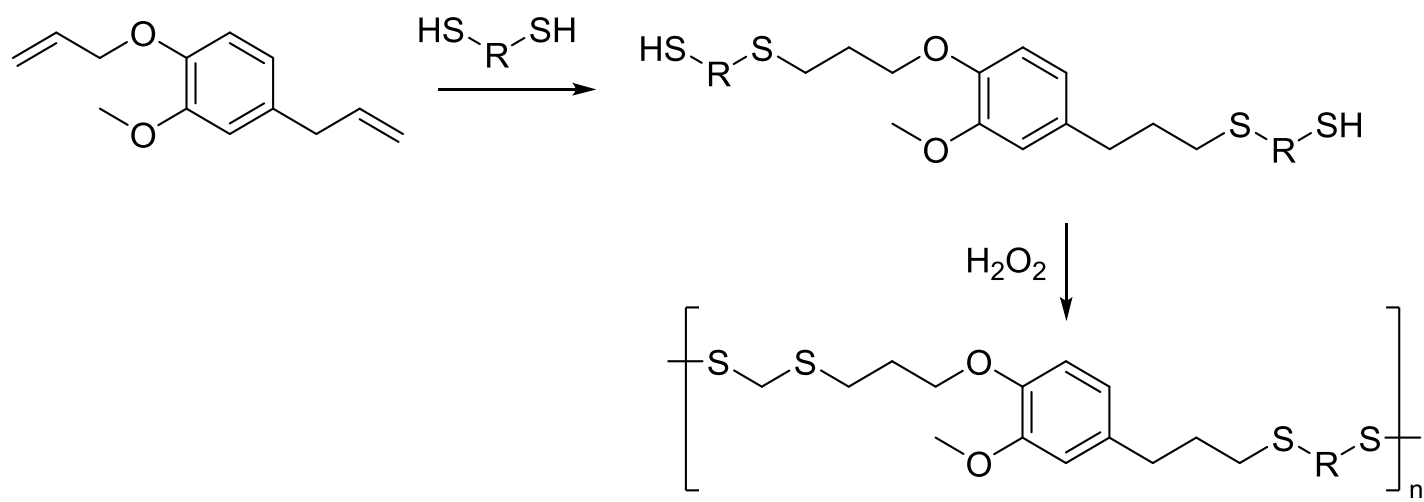

Scheme 19. Thiol-ene reaction of $A E G$ and subsequent thiol-oxidation. 


\subsubsection{Thiol-ene coupling and thiol-ene polymerization}

As mentioned before, thiol-ene "click" reaction can be used to introduce either desired functional groups through the allylic double bond or eugenol moieties into a polymer, but it can also be employed to copolymerize eugenol and eugenol-derivatives. Thiolene networks are obtained via a radical step-growth process showing a rapid chain transfer, which produces highly homogeneous networks resulting in well-defined physical and mechanical properties, such as a narrow glass transition temperature. ${ }^{174}$ In this way, Donovan et al. ${ }^{174}$ synthesized a cross-linked polymer for adhesive applications. Pentaerythritol triallyl ether was mixed with methyleugenol, eugenol and 4-allylpyrocatechol in different ratios and then they were photopolymerized with tetrathiol (pentaerythritol tetra(3-mercaptopropionate)). Full conversion was observed for the methyleugenol while a decrease in conversion occurred in the presence of phenolic hydroxyl group (more significantly with the catechol function due to the radical scavenging effect of the phenolic hydroxyl groups). The $T g$ and Young's modulus of resulting materials decreased with the increase of the eugenol, methyleugenol or 4-allylpyrocatechol content, since the cross-linking density decreased and the presence of more free chain ends into the network increased with eugenol or eugenol-derivatives content.

Thiol-ene reaction was also used to graft eugenol-derivatives onto polymer chains containing olefins such as polybutadienes as shown in Scheme $20 .^{81,82}$ The synthetic strategy consisted in the functionalization of the allylic position of silyl-protected eugenol with a dithiol by slow addition of eugenol in a large excess of the dithiol, and then grafting the resulting molecule by a thiol-ene reaction onto polybutadiene. The molecular weight of the polymers increased with the grafting, and the glass transition temperature decreased reaching -33 to $-35{ }^{\circ} \mathrm{C}$. Deprotection of the eugenol moieties was carried out in acid medium to yield a catechol group, leading to polymers with higher glass transition temperatures $\left(3\right.$ to $\left.10^{\circ} \mathrm{C}\right) .{ }^{81}$

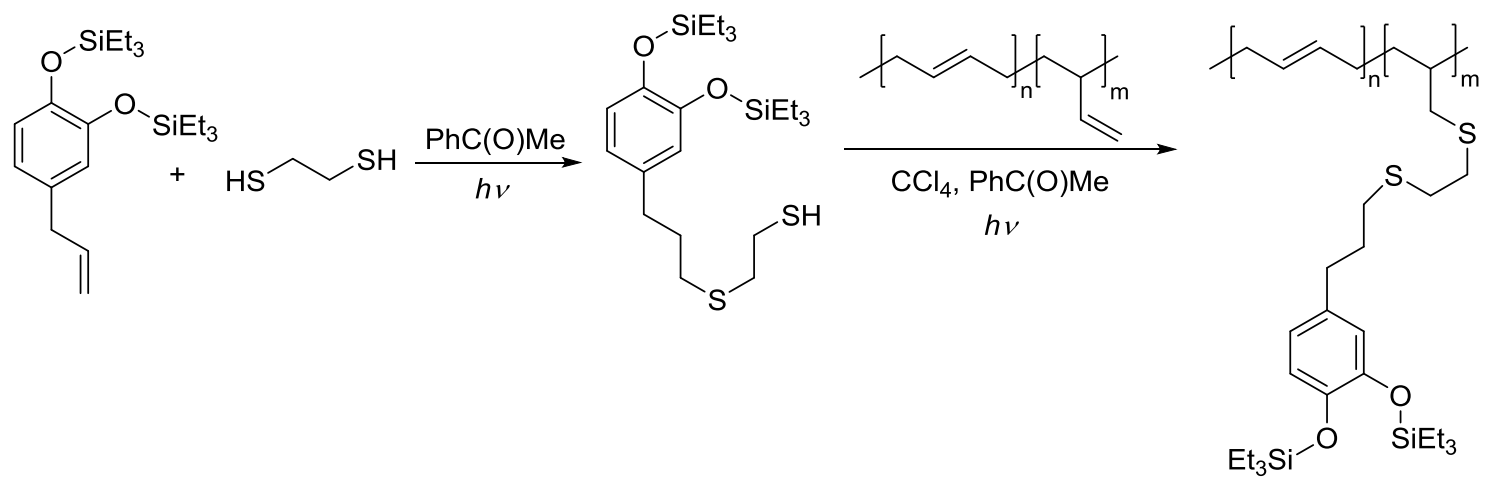

Scheme 20. Grafting of eugenol-derived methacrylates to polybutadiene. 
Similarly, inspired on the adhesive proteins of mussels, which possess a catechol moiety in their structure, Heo et al. $^{73}$ published the synthesis of a polysiloxane functionalized with silyl-protected cathecolic groups starting from eugenol. The synthetic strategy consisted of the protection of hydroxyl group of eugenol by silylation with triethylsilane. Note that this reaction not only protects the phenolic hydroxyl group of eugenol to prevent the interference of this group in the thiol-ene reaction, but also converts the methoxy group on a protected phenolic hydroxyl group, leading to a protected cathecolic group. Subsequently, thiol-ene reaction was carried out with poly(mercaptomethyl)siloxane and using DMPA as photoinitiator. The silyl protecting groups serve to provide a long shelf life to the assembled materials. Moreover, the silyl-protected catecholic functions can be deprotected under mild acidic or basic conditions, allowing to modulate the catechol-mediated adhesion by the ratio of protected and deprotected cathecolic hydroxyl groups, which is highly effective for underwater adhesion systems.

Thiol-ene coupling and polymerization reactions allowed to prepare highly cross-linked networks with AEG and a trithiol such as trimethylolpropane tris(3mercaptopropionate), also incorporating eugenol and linalool molecules. ${ }^{121}$ This technique produced cross-linked materials with antibacterial and antioxidant properties. The presence of native eugenol with free phenolic groups promoted the anti-adhesion bacterial activity and led to antioxidant properties. The produced biobased materials were not affected by water penetration under high moisture conditions.

In addition, the same research team prepared a composite material by cross-linking AEG with trithiols incorporating $\mathrm{ZnO}$ nanoparticles. The material exhibited antibacterial properties enhanced by the presence of $\mathrm{ZnO}^{120}$ The authors claimed that the elaboration of bioactive surfaces for medical applications could be envisaged. Photocuring technique also allowed to synthesize antioxidant and antibacterial networks containing bioactive molecules such as carvacrol or tannic acid with a potential use for packaging application. ${ }^{122,123}$ Surprisingly, while carvacrol (up to $20 \%$ $w / w)$ acts as plasticizer, diminishing the $T_{\alpha}$, it rises the Young's modulus. Carvacrol also produces a higher cross-linking density attributed to the presence of physical cross-link nodes. $^{123}$

A similar procedure was used by Dai et al. ${ }^{119}$ to prepare cross-linked networks with AEG, diallyl itaconate (synthesized from itaconic acid and allyl bromide) and a trithiol. The curing was carried out under UV irradiation, leading to films with antibacterial properties and with higher tensile strength, modulus and glass transition temperature when increasing the content of diallyl itaconate. These three different polymerizations using AEG are depicted in Scheme 21. 


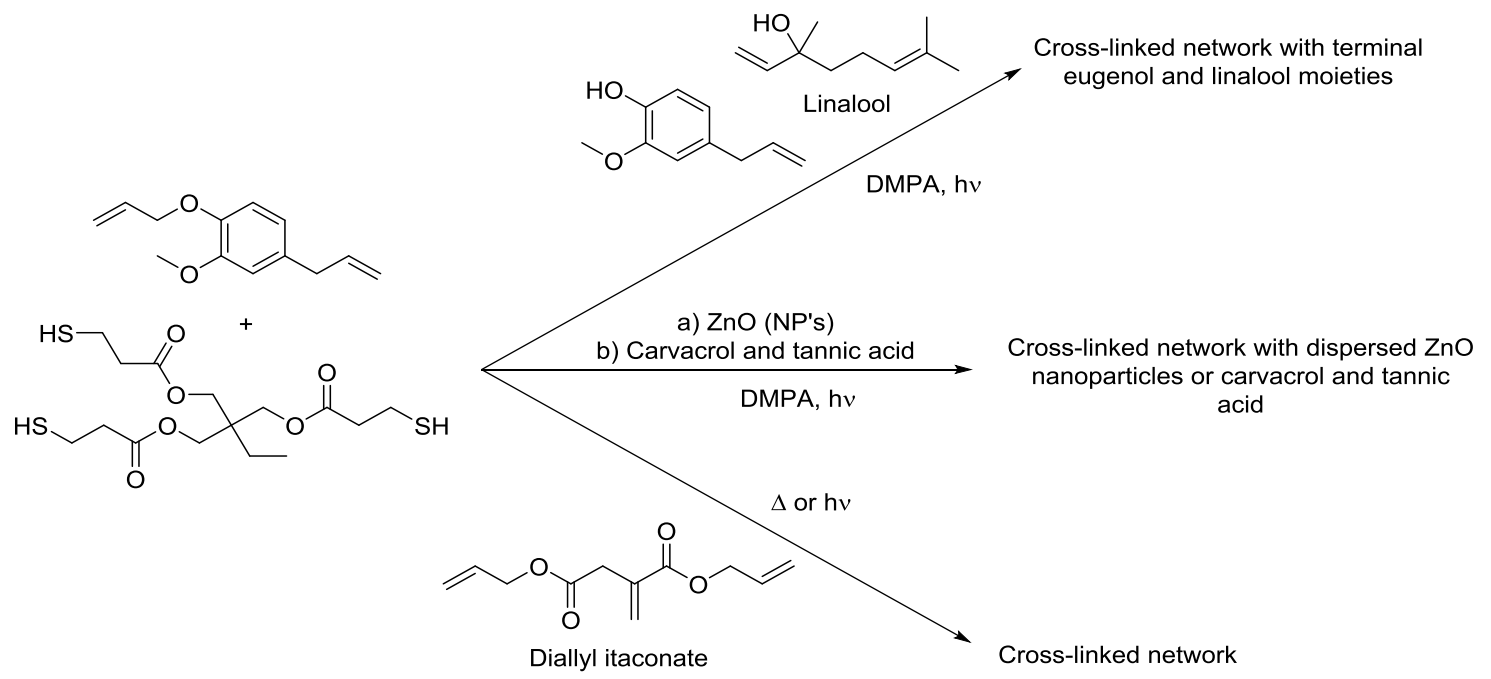

Scheme 21. Different thiol-ene polymerization reactions using allyl-etherified eugenol.

Miao et al. ${ }^{175}$ reported the synthesis of a fully biobased triallyl eugenol-derivative by a one-step sustainable method, consisting in the nucleophilic substitution reaction of $\mathrm{P}-\mathrm{Cl}$ bonds of phosphoryl chloride and the hydroxyl group of eugenol in water. The resulting compound, trieugenol phosphate (TEP) was cross-linked through thiol-ene coupling with a di-, tri- and tetra-thiol leading to networks with high cross-linking densities and remarkable thermal properties, especially for the highest cross-linking densities obtained with the tetra-thiol (pentaerythritol tetrakis(3mercaptopropionate)). The authors claimed potential applications in high-performance flexible transparent materials and as stereolithographic 3D print material.

\subsubsection{Thiol-epoxy polymerization}

Although previous examples relate to eugenol as the alkene in the thiol-ene reaction, it can be also functionalized to produce thiols as shown by Guzmán et al. ${ }^{116,176}$ In this work, the authors described the preparation of various eugenol-based monomers, including eugenol-based tri-thiols (via an allylation, followed by the reaction with thioacetic acid and then a saponification), and their curing process through both thiolene reaction and thiol-epoxy dual curing using a eugenol glycidyl derivative. The dual curing led to the improvement of thermal and mechanical properties such as the $T_{g}$ (up to $57^{\circ} \mathrm{C}$ ), the stiffness and the tensile strength.

\subsubsection{Epoxy resins}

Epoxy resins are among the most versatile thermosetting polymers and they are widely used in many industrial and domestic products because of their remarkable properties. ${ }^{177,178}$ However, a large majority of epoxy resins are manufactured currently from petroleum-based monomers such as bisphenol A diglycidyl ether (DGEBA) obtained from bisphenol A (BPA) and epichlorohydrin. Besides not being renewable raw materials, both reagents are considered toxic and harmful to health. Biobased 
epoxy resins are considered promising materials, which can exhibit similar or even better properties that petroleum-based ones. ${ }^{177}$ Since eugenol is a biobased phenolic monomer which can be functionalized with one or more epoxide groups, it is a potential candidate to substitute BPA in epoxy resins. For instance, Qin et al. ${ }^{179}$ synthesized a eugenol di-epoxide monomer and cured it using hexahydrophthalic anhydride (HHPA) and a biobased rosin-derived anhydride named maleopimaric acid (MPA). The resulting material was compared with a material synthesized with a DGEBA commercial epoxy resin (D.E.R. ${ }^{\mathrm{TM}}$ 353, Dow $^{\circledR}$ ) and cured with the same curing agents, and it was concluded that both materials exhibited similar thermal and mechanical performances.

Alternatively, Wan et al. developed a few eugenol-derived epoxy monomers based on the di- or tri-merization of eugenol through its phenolic hydroxyl function with an aromatic diacyl chloride, ${ }^{180}$ an aromatic dichloride ${ }^{181}$ or by the formation of a cyanurate ring. $^{87}$ The curing process was carried out with 4,4'-diaminodiphenyl methane (DDM) and 3,3'-diaminodiphenylsulfone (33DDS) as shown in Scheme 22.

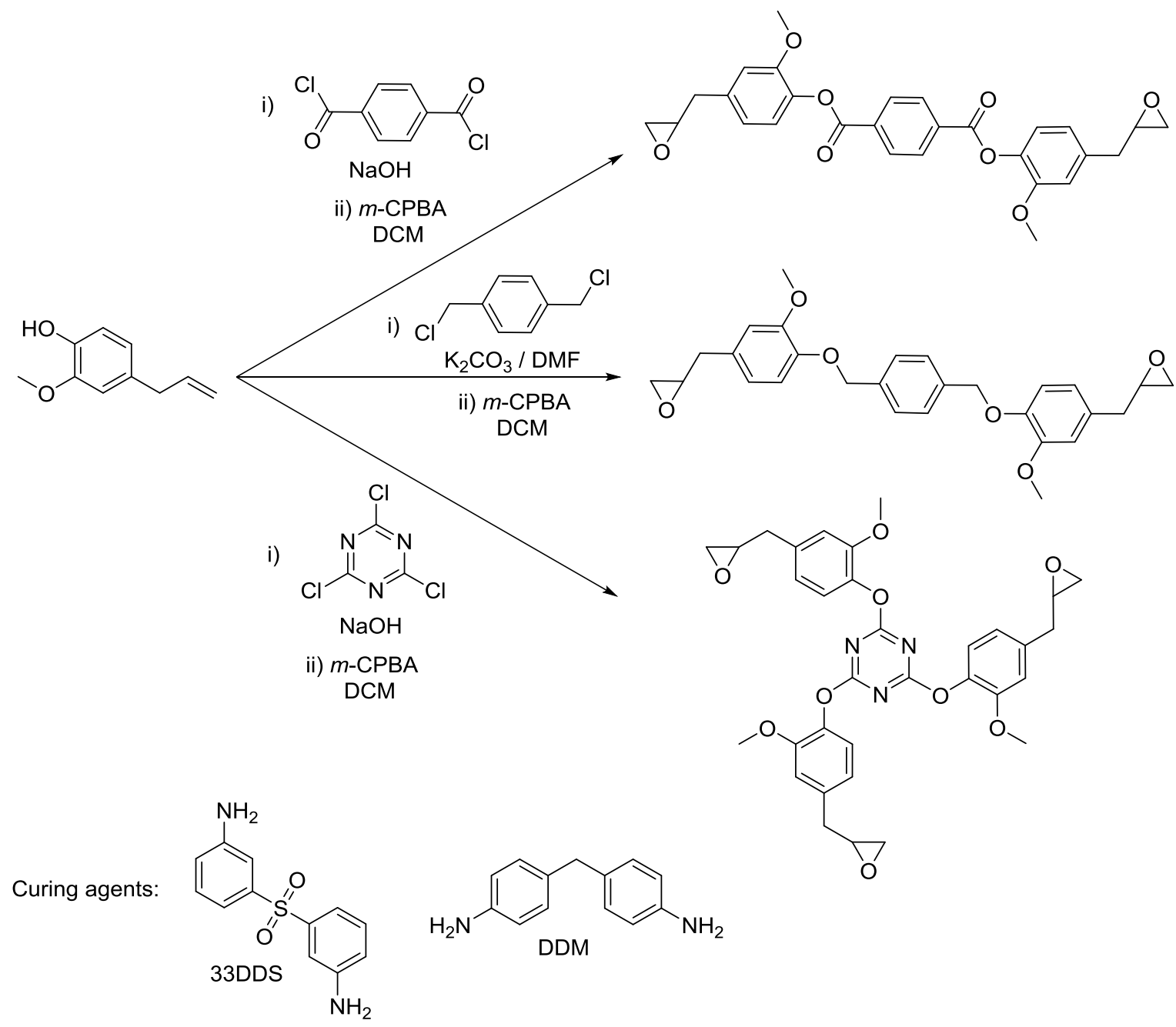

Scheme 22. Synthesis of eugenol-derived di and tri-epoxy monomers. 
The resulting materials were compared with the epoxy resins obtained from DGEBA and using the same curing agents. The results showed that the eugenol-derived epoxy resins exhibit comparable or even better thermal and mechanical properties, such as higher char yield and lower flammability.

Phosphorous is well-known to contribute to the flame retardancy properties of materials, avoiding the use of halogens. ${ }^{182,}{ }^{183}$ Thus, the introduction of phosphorous in eugenol-derivatives monomers can be interesting to obtain thermosets with high char yields and with potential application as flame retardant materials. For instance, our research team synthesized and characterized eugenol-based thermosets with trieugenyl phosphate (TEP), which was obtained by the reaction of eugenol with phosphoryl chloride $\left(\mathrm{POCl}_{3}\right)$ in the presence of triethylamine (Scheme 23). ${ }^{88,}{ }^{184}$ Subsequent epoxidation with $m$-CPBA yields triepoxidized eugenyl phosphate (TEEP), which was employed as epoxy resin cured with an aliphatic diamine (Jeffamine ${ }^{\circledR}$ EDR$148)$ and with an aromatic one ( $m$-xylylenediamine, MXDA). Both materials exhibit good thermal and mechanical properties as well as high char yields and thus they have a potential application as flame retardant materials.

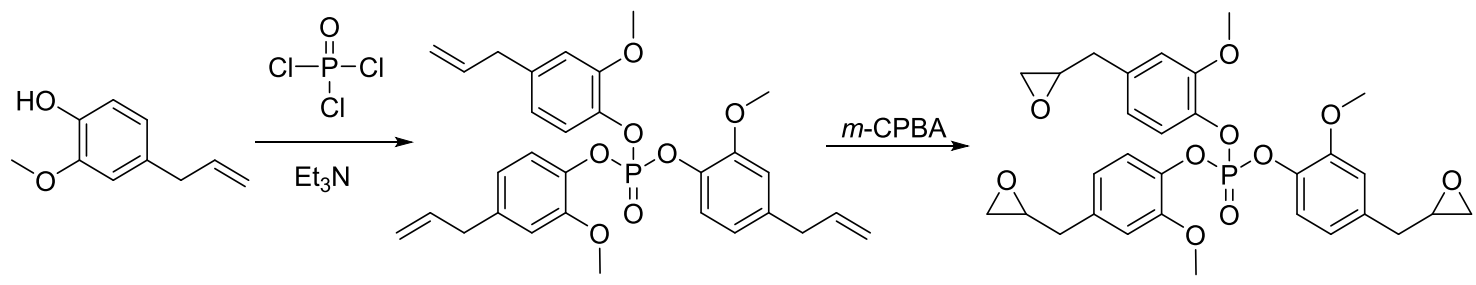

Scheme 23. Synthetic pathway of tri(epoxized-eugenyl) phosphate (TEEP). ${ }^{88}$

Miao et al. $^{86}$ reported the preparation of a high biomass content epoxy resin synthesized from eugenol and 2,5-furandicarboxylic acid using an eco-friendly synthetic route. The curing process was performed with methyl hexahydrophthalic anhydride (MHHPA). Because of the presence of phenyl and furan aromatic groups in the structure, the resulting material exhibited a remarkable high $T_{\mathrm{g}}$ (over than $153^{\circ} \mathrm{C}$ ), thermomechanical properties and flame retardancy compared to materials obtained from DGEBA epoxy resin.

More recently, Tian et al. ${ }^{78}$ prepared a shape memory polymer starting from the diglycidyl ether of eugenol-2-mercaptoethanol and the diglycidyl ether of vanillyl alcohol (DGEVA) cured with DDM. The resulting network is composed of soft segments produced by the aliphatic moieties and hard segments from the aromatic groups.

\subsubsection{Ene reaction}

Ene reaction, also known as Alder-ene reaction, was discovered by Kurt Alder in 1943. ${ }^{185}$ This pericyclic reaction consists in the reaction between an alkene and an allylic hydrogen. ${ }^{186}$ Thus, the allyl group of eugenol can react with an alkene through ene reaction. Maleimide is commonly employed in the ene reaction due to its exceptional reactivity. Cured BMI resins possess interesting properties such as high $T_{\mathrm{g}}$, 
good hot-wet performance as well as low flammability. ${ }^{187}$ Moreover, the thermal addition polymerization of BMIs does not produce any elimination product, making these polymers interesting for composite materials.

Gaina et al. ${ }^{188}$ reported the synthesis of a few allyl-maleimide and allyl-citraconimide monomers containing a eugenol moiety (Scheme 24). Curing process of these monomers was carried out thermally by ene and Diels-Alder reactions, leading to polyesters with a notable thermal stability.<smiles>[R]C1=CC(=O)N(c2ccc(C(=O)Oc3ccc(CC=C)cc3OC)cc2)C1=O</smiles>

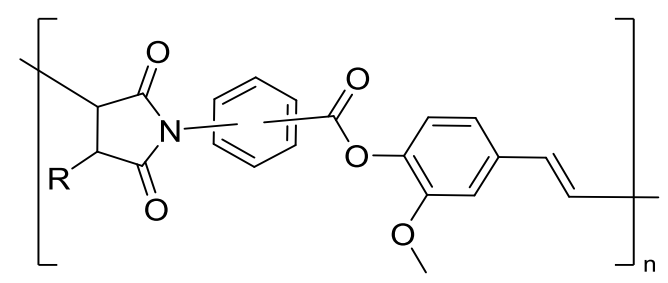

Scheme 24. Eugenol-derived monomer ene polymerization.

A different strategy to obtain BMI resins consists of the formation of a eugenol dimer containing two allyl functions by the reaction of eugenol with succinic acid, ${ }^{189}$ to be subsequently reacted with BMIs (synthesized from $\mathrm{p}$-hydroxyphenylmaleimide and succinyl chloride). The curing reaction proceeded by heating a mixture in different ratios of both products. Another BMI resin was also prepared with 2,2'-diallyl bisphenol $A$ and 4,4'-bismaleimidediphenylmethane in order to compare the properties of both resins cured under the same conditions. While the petroleum-based resin exhibited better thermal and mechanical properties when fully cured under severe conditions, the biobased thermosetting resin was curable at lower temperature and shorter time than the diallyl bisphenol A resins.

Neda et al. ${ }^{112}$ prepared BMI resins from allyl eugenol (AEG) and allyl bis-eugenol (ABEG) obtained by oxidative coupling. The resulting BMI resins exhibited extraordinary thermal and mechanical properties. The $T_{\mathrm{g}}$ values and the thermal stability increased with increasing of BMI content. Additionally, the pyrolysis of AEG produced 2,4-diallyl-6-methoxyphenol by Claisen rearrangement, whereas pyrolysis of ABEG led to either elimination or rearrangement to the free position adjacent to the phenolic group by an out-of-ring Claisen rearrangement. On the other hand, Shibata et al. ${ }^{113}$ reported the synthesis of biobased aliphatic polyol-derived polymaleimides and their polymerization with AEG to obtain thermosetting resins with a high biobased content and good thermal resistance, but lower than the AEG/BMI resins. 


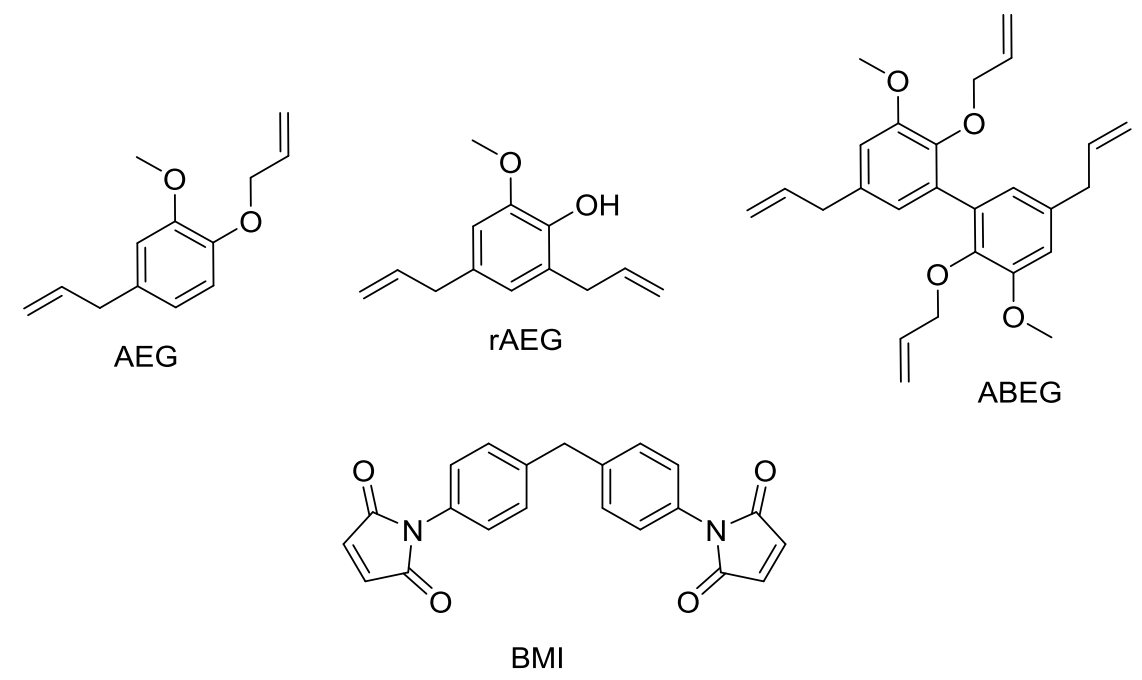

Scheme 25. Different eugenol derived monomers used in ene polymerization with BMI.

Alternatively, TEP was also cured by ene reaction with $N, N^{\prime}-1,3-$ phenylene bismaleimide (PhBMI) and a linear maleimide terminated polydimethylsiloxane (SiBMI). ${ }^{184}$ The resulting materials exhibited remarkable properties such as very low $T_{g}$ $\left(-113^{\circ} \mathrm{C}\right.$ for SiBMI) or very high char yield (60\% for PhBMI).

Ene reaction was also used to enhance properties of other eugenol-based networks such as benzoxazines. ${ }^{190}$ The allylic double bond is able to react with the maleimide group through ene reaction. The polymerization between a eugenol-derived benzoxazine and BMI was performed. Depending on the concentration of BMI, the thermal and mechanical properties can be modulated. Additionally, the properties of this system were improved by the addition of a limited amount of carbon nanotubes (CNTs) to form composites which are very promising materials for aerospace and micro-electronics applications. Indeed, eugenol-based bis-maleimide (BMI) resins have been synthesized to produce high performance biobased bis-maleimide resins and networks. ${ }^{112,158,189,191}$

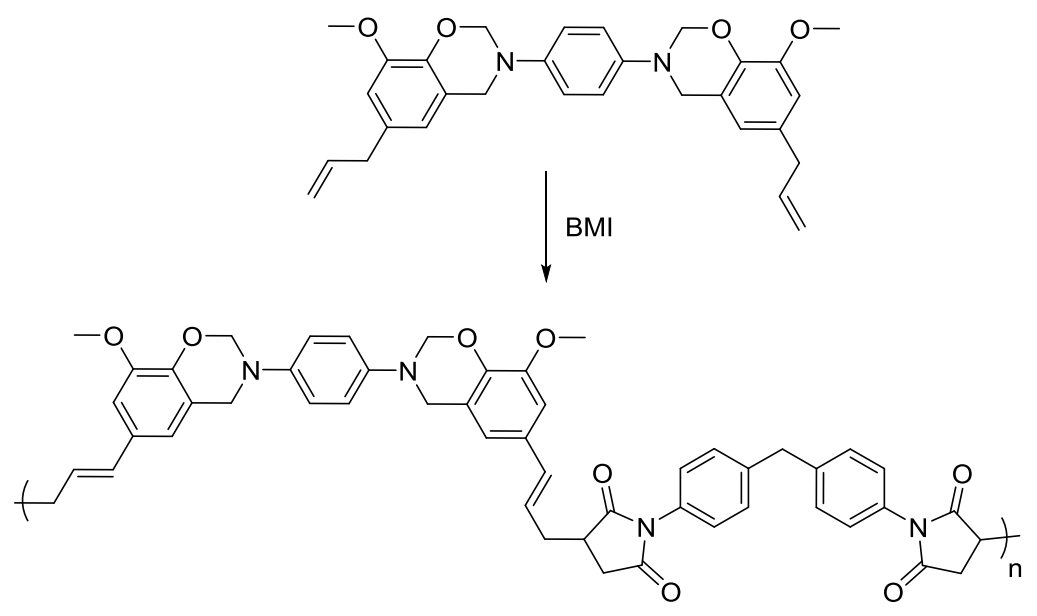


Scheme 26. Bezoxazine eugenol-derived monomer used in ene polymerization with BMI.

Zhang et al. ${ }^{192}$ prepared a star-shaped cyclotriphosphazene eugenol derivative (hexaeugenolcyclotriphosphazene, HECTP, Scheme 27), which contains six allyl functional groups. The synthetic strategy consisted in the reduction of eugenol with metallic sodium to obtain sodium eugenolate, which reacts with hexachlorocyclotriphosphazene. This molecule was subsequently cured with BMI leading to a bismaleimide resin with a limiting oxygen index (LOI) of $39 \%$ and thus excellent flame retardancy properties as well as a good mechanical properties and thermal stability (more than $60 \%$ of residues at $850{ }^{\circ} \mathrm{C}$ ). An alternative synthetic pathway to obtain HECTP using potassium carbonate instead of metallic sodium was recently published. ${ }^{193}$ Additionally, in this study HECTP was cured by thiol-ene reaction with di-, tri- and tetra-functionalized thiol monomers, leading to materials with outstanding thermal and mechanical properties and high transparency. Monisha et al. ${ }^{194}$ reported the curing process of HECTP by the ROP of liquid elemental sulfur $\left(\mathrm{S}_{8}\right)$ at $180^{\circ} \mathrm{C}$. The resulting material exhibited remarkable properties as flame retardant and potential application as a cathode material in high-performance Li-S batteries for tropical countries.

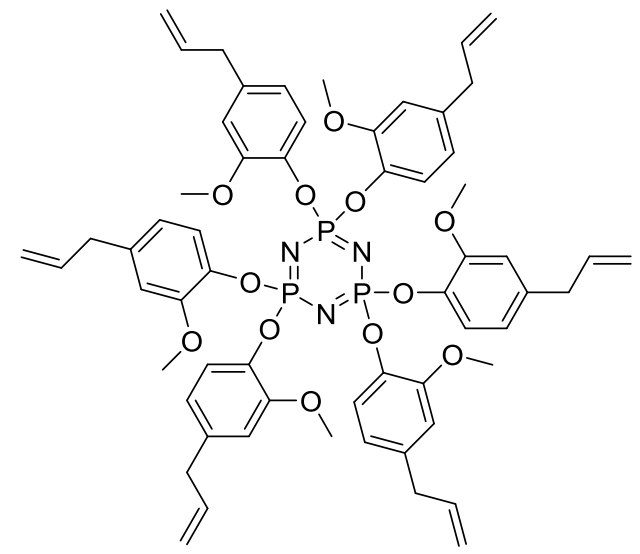

Scheme 27. Chemical structure of HECTP.

On the other hand, HECTP was employed for the synthesis of polybenzoxazines by the reaction with a cardanol based tris-benzoxazine. ${ }^{195}$ The curing reaction of the mixture yielded a hydrophobic benzoxazine resin which exhibited high flame retardant efficiency and with great potential to replace many other flame retardant.

\subsubsection{Benzoxazines}

Benzoxazines are molecules with an oxazine ring (a six-membered ring containing an oxygen and a nitrogen) attached to a benzene ring. The oxygen and nitrogen can be in 
different positions of the ring, however the term benzoxazines is usually referred to the 1,3-benzoxazines. Benzoxazines are readily synthesized by a Mannich-like condensation of a phenol-derivative, a primary amine and formaldehyde. Benzoxazines polymerize by thermally activated ring-opening polymerization, with or without catalyst, and with a cationic initiator or by simple heating, leading to polybenzoxazines. These polymers are a relatively new class of polymeric phenolic resins with unique properties such as near-zero shrinkage, low moisture absorption, high glass transition temperatures and very high char yields, making them attractive for many applications such as microelectronics, aerospace industry, and in fuel cells. ${ }^{196,}{ }^{197}$ Eugenol could be a potential precursor to synthesize benzoxazine resins since it possesses a phenolic hydroxyl function in its chemical structure. ${ }^{198}$ However, eugenol is an aromatic compound where the para and one of the ortho positions relative to phenolic hydroxyl group are already occupied. As the privileged site for the ring-opening polymerization of benzoxazines is the ortho position and to a lesser extent para position, the crosslinking reaction of eugenol-based benzoxazines should not occur. Nevertheless, the use of a mixture of symmetric and hybrid eugenol and phenol bis-benzoxazines yielded a crosslinked network whose crosslink density can be modulate with the eugenol content. ${ }^{199}$ Alternatively, the allyl function is able to react with the maleimide group through ene reaction. ${ }^{190}$ Indeed, eugenol-based bis-maleimide (BMI) resins have been synthesized to produce high performance biobased bis-maleimide resins and networks. ${ }^{112,158,189,191}$ Thirikumaran et al. ${ }^{200}$ reported the synthesis as well as the curing process of a few eugenol-based bis-benzoxazines using aromatic diamines. Interestingly, they observed that allyl moiety from eugenol also participates in the curing process improving the cross-linking density of the obtained polymers as depicted in Scheme 28, resulting in a surprisingly high thermal stability and char yield. Furthermore, eugenol-based polybenzoxazines showed antimicrobial properties and therefore have potential applications as films in food packaging industry. ${ }^{201,202}$

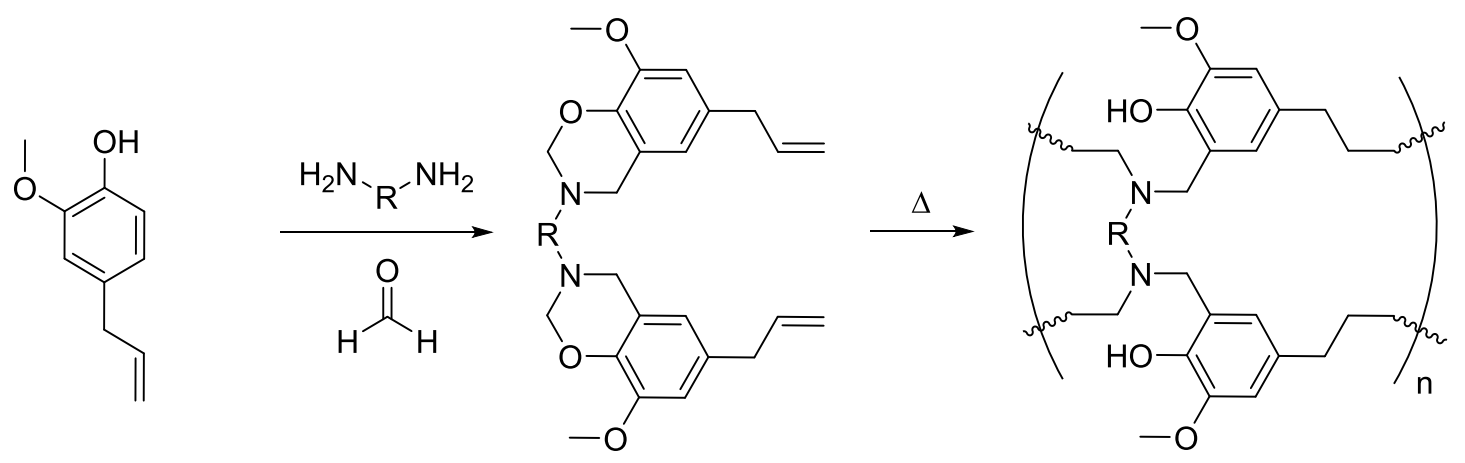

Scheme 28. Synthesis of polybenzoxazine from eugenol. 
This research group then published the synthesis of fully biobased benzoxazines synthesized from eugenol, stearyl amine and furfurylamine by an eco-friendly process without solvents. ${ }^{203,204}$ Additionally, the authors noted that the furan ring increased the cross-linking density in the polymer and the copolymer, improving the thermal and mechanical properties of the resulting polymers. These polymers exhibited a high LOI and thus good properties as flame retardancy. They were also employed to prepare biobased composites with jute fiber, previously treated to increase the interaction with the resins by the formation of inter-molecular hydrogen bonds. ${ }^{204} \mathrm{~A}$ similar strategy was followed by Amarnath et al., ${ }^{205}$ who employed eugenol, isoeugenol, furfurylamine and paraformaldehyde to synthesize eugenol and isoeugenol-based benzoxazines. The curing behavior and the thermomechanical properties of resulting crosslinked materials were compared. Interestingly, the curing reaction of isoeugenolbased benzoxazine was notably faster than the one of eugenol-based benzoxazine due to the conjugation of the double bond with the aromatic ring. A higher $T_{g}$, storage modulus and better adhesion properties were also observed for the isoeugenol-based crosslinked benzoxazine due to the shorter chain length.

\subsubsection{Phenolic resins}

Phenolic resins are synthetic polymers obtained by addition-condensation of phenol or a phenol-derivative with formaldehyde. These resins have dominated the field of thermosetting polymers for many decades because of their versatility, low production cost, thermal stability, and the ease of their production. They are widely used to manufacture circuit boards, wood and wood fiber panels and molded products among many other applications. ${ }^{206}$ Since eugenol is a substituted phenol, it can be used as an eco-friendly alternative to the toxic and harmful phenol. There are two kinds of phenolic resins: novolac, where the phenol/formaldehyde molar ratio is higher than one and the resoles, where the phenol/formaldehyde molar ratio is lower than one. There are a few examples of the synthesis of eugenol novolac; however, to the best of our knowledge, eugenol resoles have not been reported yet.

Sakamoto et al. $^{207}$ pioneered in the synthesis of a few new novolacs from natural phenolic compounds such as vanillin, vanillin derivatives and eugenol. They used the acid-catalyzed phenol-formaldehyde condensation with eugenol, formaldehyde, and concentrated hydrochloric acid or sulfuric acid in acetic acid to obtain eugenol novolac in quantitative yield as displayed in Scheme 29.

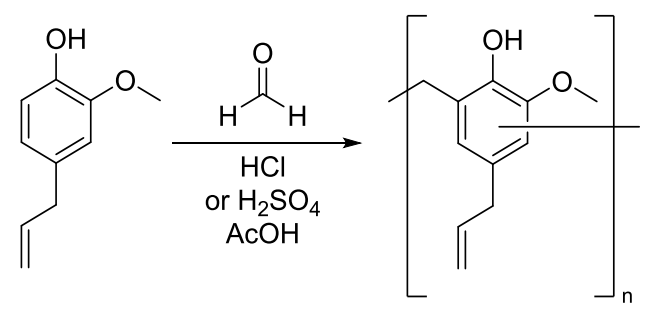

Scheme 29. Polycondensation of eugenol with formaldehyde. ${ }^{207}$ 
More recently, Shibata et al. ${ }^{158}$ reported the synthesis of eugenol novolac by a similar procedure, leading to eugenol oligomers. These oligomers were subsequently cured by ene reaction with different amounts of BMIs. The resulting materials possess properties that varies with the BMI content, such as the flexural strength, and especially the $T_{\mathrm{g}}$ and the thermal stability. This research team also published the synthesis of a eugenol-derived epoxy resin from O-glycidylated eugenol novolac cured photo-thermally by simultaneous thiol-ene, thiol-epoxy and thiol-maleimide reactions. ${ }^{130}$ Moreover, the synthesis of silicon-modified phenolic novolacs from a eugenol-derivative functionalized with a siloxane, phenol and formaldehyde was achieved by Li et al. ${ }^{208}$ The resulting material was used as resin matrix with sisal fiber to form a composite exhibiting excellent electrical resistance, low water absorption and high thermal stability.

\subsubsection{Olefin metathesis}

Polymerization of eugenol derivatives containing two olefin functions (eugenol dimerized through the phenolic hydroxyl group by different linkers or 4-allyl-1-(but-3en-1-yloxy)-2-methoxybenzene) was achieved with high conversions by acyclic diene metathesis (ADMET) polymerization using a second generation Grubbs' catalysts, with and without solvent. ${ }^{209}$ The authors noted that for some employed monomers, a partial isomerization of the phenyl allyl group occurred during the polymerization, especially for high reaction times.

A different strategy to obtain eugenol-based polyesters was proposed by Le et al. ${ }^{210}$ involving the formation of a diallyl compound by the reaction of the phenolic hydroxyl group of eugenol with 10-undecenoyl chloride, a biobased unsaturated acyl chloride obtained from castor oil. Then, ADMET polymerization of the resulting molecule was carried out with second generation Grubbs' catalyst, resulting in a fully biobased polyester (Scheme 30).
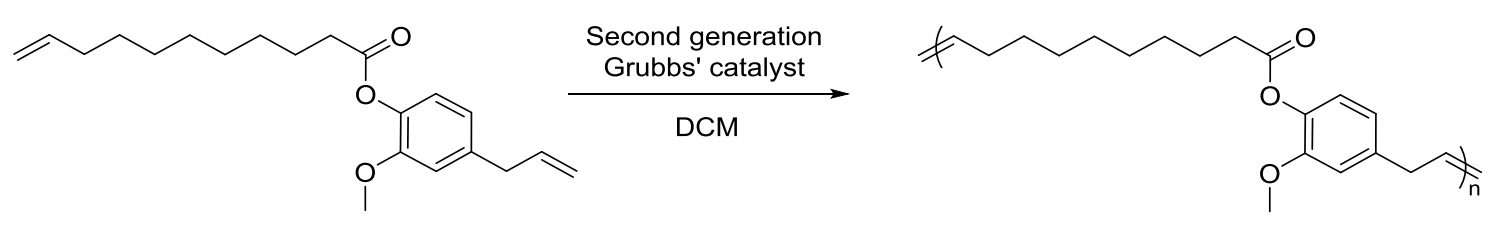

Scheme 30. Eugenol-derived polyester synthesized through ADMET polymerization.

Chapala et al. ${ }^{81}$ carried out the functionalization of 1,2-polybutadiene with eugenol with first- and second-generation Grubbs' catalysts. In this case, they used a triethyl silyl-protected eugenol to perform the cross-metathesis reaction because of the higher reactivity of the protected eugenol in cross-metathesis and to prevent the formation of insoluble crosslinked polymers due to intra- and inter-molecular hydrogens bonds, according to the authors. 


\subsubsection{Polyesters}

Polyesters are multifunctional materials with a multitude of industrial applications, especially in the clothing industry. They can be synthesized by several methods such as condensation, acylation, or transesterification, among others. Hu et al. ${ }^{84,211,212}$ reported the synthesis of a few eugenol-based precursors of polyesters obtained by thiol-ene coupling of eugenol with methyl thioglycolate, followed by an alkylation of the phenolic group with methyl chloroacetate, or by a dimerization of the eugenolderived ester with 1,4-bibromobutane (Scheme 31).<smiles>COC(=O)COc1ccc(CCCSCC(=O)OC)cc1OC</smiles><smiles>COC(=O)CSCCCc1ccc(OCCOc2ccc(CCCSCC(=O)OC)cc2OC)c(OC)c1</smiles>

Scheme 31. Eugenol-derived diesters prepared by Hu et al. ${ }^{211}$

Subsequent polymerization was carried out by transesterification and two-step melt polycondensation with linear aliphatic diols such as ethylene glycol or 1,4-butanediol, among others, leading to thermoplastic polyesters with remarkable thermal stabilities and mechanical properties. A deeper study correlating the chemical microstructures of these copolymers with the thermal and crystalline properties was carried out by this research team. ${ }^{213}$ Consequently, these materials have the capability to substitute the currently used petroleum-based polyesters such as polyethylene terephthalate (PET) or polybutylene terephthalate (PBT). In addition, the insertion of a phenoxy-ether in the structure enhanced toughness of polyesters. ${ }^{214}$

\subsection{Chain growth polymerization}

\subsubsection{Cationic polymerization of eugenol}

There are a few examples of cationic copolymerization of eugenol in the literature. Eugenol and lauryl methacrylate copolymers were obtained by Fajrin et al. ${ }^{215}$ by cationic polymerization using sulfuric acid as initiator. On the other hand, Breloy et $a l^{216}$ reported the synthesis of a biobased antibacterial coating using both cationic and thiol-ene reaction with eugenol and mono- and di-epoxy limonene and with $\beta$ carotene as photosensitizer under visible-light irradiation. Additionally, the synthesis of a network with eugenol glycidyl ether and resorcinol diglycidyl ether by cationic copolymerization with UV irradiation and iodonium was published by Modjinou et al. ${ }^{133}$. The resulting network possessed the pendant allyl groups which were postfunctionalized by thiol-ene reaction with glutathione to add new properties to the material such as antibacterial and antioxidant properties.

\subsubsection{Radical polymerization}

Eugenol does not polymerize promptly through its allylic double bond as this would form highly stabilized allylic radicals. Moreover, the phenolic moiety in its structure 
acts as a radical scavenger conferring eugenol molecule antioxidative properties. ${ }^{138,217}$, 218 Therefore, suitable functional groups should be introduced to radical polymerization. Eugenyl methacrylate and ethoxy eugenyl methacrylate can homo and copolymerize, as reported by Rojo et al. ${ }^{134,139}$ who synthesized (co)polymers for applications in dentistry. It was shown that the monomers readily reacted producing high cross-linked material. Moreover, the polymeric materials exhibited antibacterial properties. Similarly, Deng et al. ${ }^{219}$ synthesized and polymerized eugenyl methacrylate through aqueous suspension polymerization. The allylic double bond was used as an additional functionality to induce cross-linking. The resulting polymer formed microspheres with diameters ranging from 500 to $800 \mu \mathrm{m}$. These microspheres exhibited a remarkable property as oil-absorbent and could be re-used at least five times.

Ding et al. ${ }^{142}$ synthesized a dimer of eugenol by thiol-ene coupling employing 3,6dioxa-1,8-octanedithiol. Subsequently, the eugenol dimer was functionalized with acryloyl chloride, leading to a diacrylate monomer (Scheme 32).

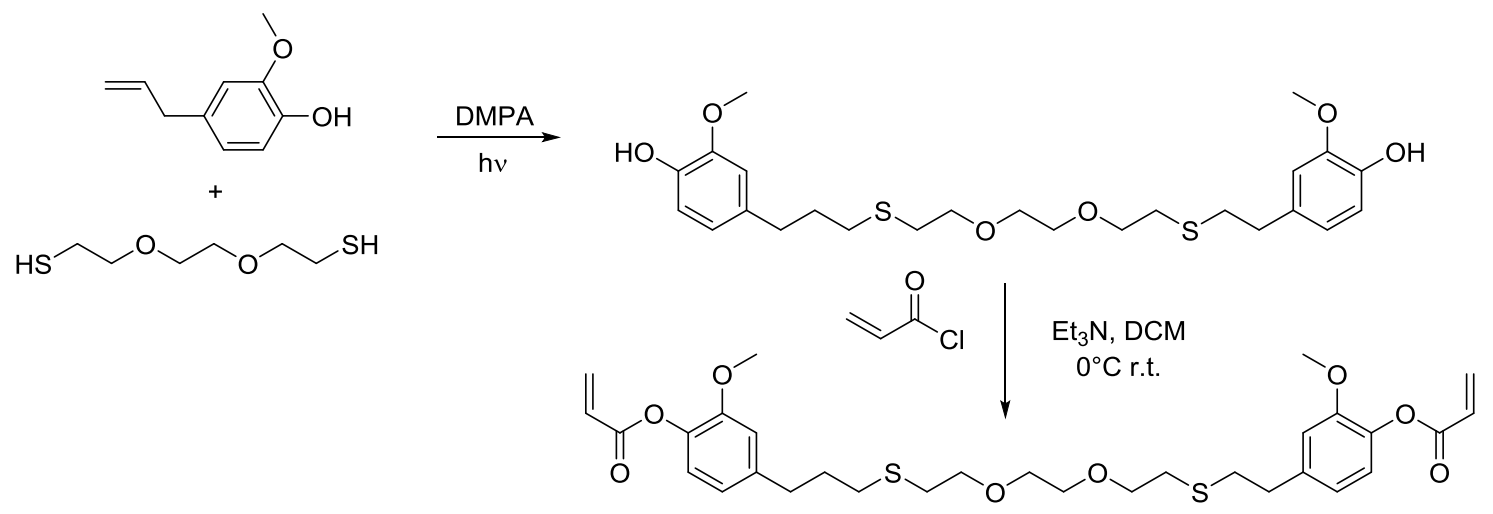

Scheme 32. Eugenol-derived di-acrylate for radical polymerization.

This monomer was copolymerized by UV irradiation with guaiacol methacrylate and with vanillyl alcohol dimethacrylate or trimethylolpropane trimethacrylate showinggood photo curing kinetics. The obtained polymers had good mechanical properties such as high modulus, tensile strength, and thermal stability. Thus, the use of eugenol-derived monomers is promising in the field of thermoset polymers for stereolithography 3D printing.

A hydrogenated eugenol-derived monomer, also known as 4-propyl guaiacol, as well as other monomers derived from syringol have been used directly after the lignin reductive depolymerization process. ${ }^{220}$ These building blocks were then acrylated using acryloyl chloride and copolymerized with butyl acrylate in reversible addition-fragmentation transfer (RAFT) polymerization process. The adhesive properties (peel and tack) of the obtained polymers were compared with some commercial products showing higher performance. 
Recently, our research team reported the synthesis of a series of eugenol derived acrylates and methacrylates ${ }^{135}$ by ethoxylation on the phenol group followed by the introduction of a methacrylate or acrylate group using methacrylic anhydride or acryloyl chloride respectively. These experiments included the use of eugenol derivatives such as isoeugenol and dihydroeugenol. The obtained eugenol-derived methacrylates were used in photoinduced polymerization, showing that the polymerization rate of the methacrylate double bonds was affected by the presence and reactivity of the allyl and propenyl groups in the eugenol- and isoeugenol-derived methacrylates, respectively. ${ }^{221}$ Furthermore, environmentally friendly aqueous emulsion polymerization of the eugenol-derived methacrylates was performed, producing stable latexes with $T_{\mathrm{g}}$ values between 20 to $63{ }^{\circ} \mathrm{C}^{136}$ In addition, the copolymerization of eugenol and dihydroeugenol-derived methacrylates was performed with commercial monomers to obtain latexes for adhesive applications, with properties comparable to a commercial product. ${ }^{222}$

\section{CONSLUSIONS AND PERSPECTIVES}

The interest for biobased polymers and thus the demand of biobased monomers has not stopped growing in recent years. Natural monomers containing aromatic, and especially phenolic groups, are really appreciated since the resulting material possess remarkable thermal and mechanical properties. There are several natural phenolic compounds obtained from different sources such as vanillin and its derivatives, syringaldehyde, ferulic and caffeic acids, cardanol and eugenol. Among them, eugenol, a natural phenol coming from clove oil, but also accessible through the depolymerization of lignin, rises as a very interesting building block for the synthesis of more sustainable materials. Its versatile chemical structure allows to execute a broad variety of functionalization reactions which give access to a platform of new multifunctional biobased molecules. By their own reactivity or combined with other reactants, these eugenol-based molecules open the possibility to explore and create precursors for a wide range of applications. Moreover, eugenol exhibit a high aromatic density compared to other natural phenolic compounds such as ferulic acid, caffeic acid and cardanol, leading to materials high thermal and mechanical performances. Even if vanillin and syringaldehyde present a higher aromatic density than eugenol, the absence of a short alkyl chain led to an exceedingly high aromatic density of the resulting materials, which are usually harder and more fragile. Furthermore, the production volume of biobased vanillin and syringaldehyde is lower than eugenol, making these phenolic monomer precursors more expensive and then less attractive to the industry. On the other hand, cardanol is also a remarkably interesting natural phenolic source, since is an inexpensive and relatively abundant raw material with several reaction sites which can be functionalized. Nevertheless, cardanol is a mixture of different molecules and its long alkyl chain provokes that the thermal and mechanical properties exhibited by the materials are less interesting. Ferulic and caffeic acids also exhibit various advantages of eugenol, such as a moderate price and 
a large production volume, as well as a good balance between functionality and aromatic density. However, the presence of acid functions makes them less attractive. Thus, among the different natural phenolic compounds, eugenol is the best compromise between aromatic density, abundance, price, and functionality, as summarized in Figure 1.

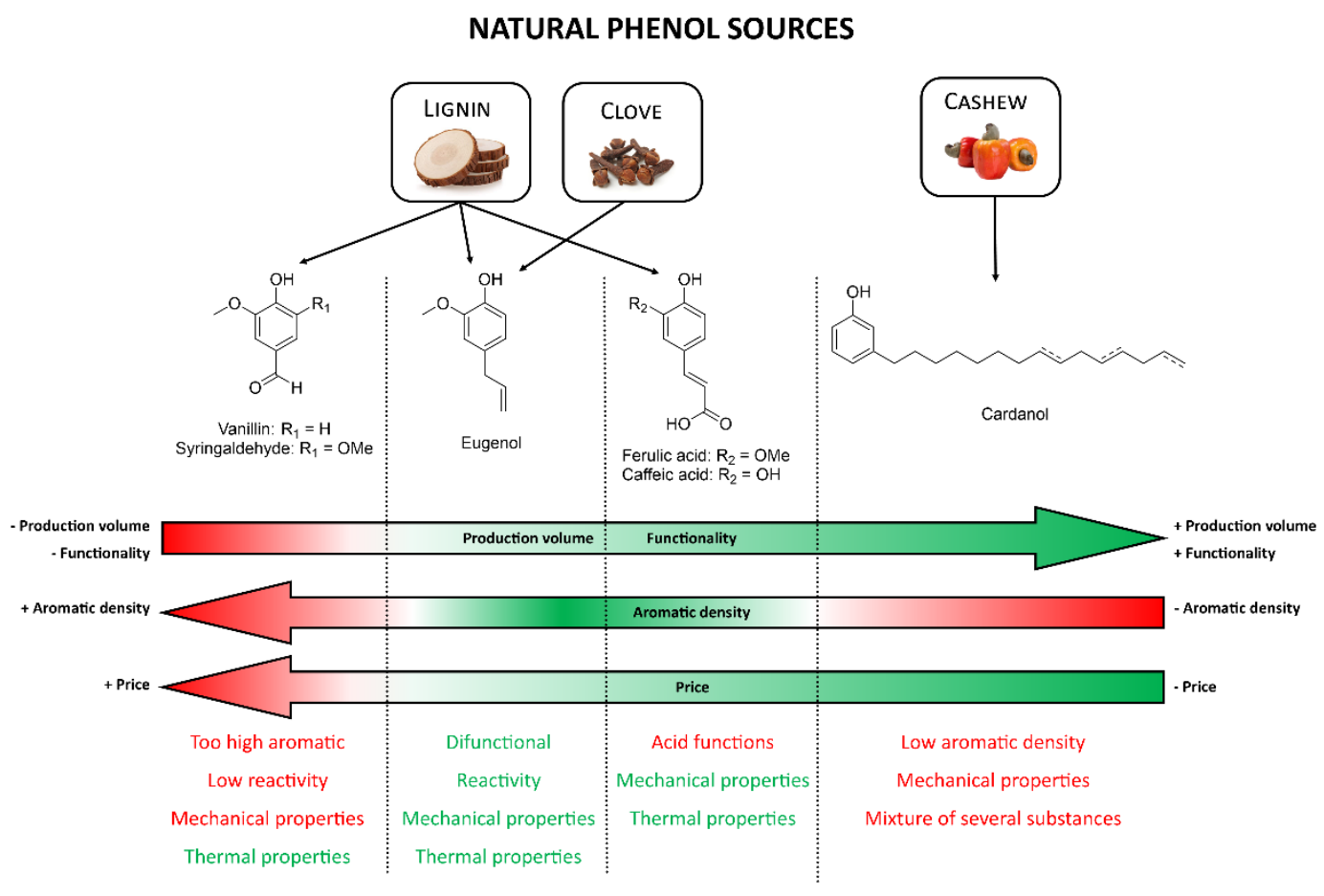

Figure 1. Comparison between different natural phenol precursors.

Although there are many options to succeed in the introduction of specific functional groups in the eugenol-based molecules, synthetic pathways that avoid or minimize the use of toxic reagents should be preferred. For instance, we can cite the use of Oxone ${ }^{\circledR}$ or hydrogen peroxide to replace oxidants such as $m$-CPBA to produce epoxy, or the use of low toxicity reagents in the alkoxylation like the use of ethylene carbonate instead of chloroethanol. Similarly, atom- and energy-efficient and solvent-free reactions or using non-toxic solvents should be favored. A good example is the use of the thiol-ene reactions that can be triggered thermally but also by light and could be solvent-free. ${ }^{72}$

Several examples of polymeric materials have been listed in this review, including polyurethanes (also non-isocyanate polyurethanes), phenolic resins, epoxy resins, polyesters and polybenzoxazines. Moreover, polymers obtained from thiol-oxidation, thiol-ene coupling and polymerization, thiol-epoxy condensation, ene reaction, olefin metathesis as well as cationic and radical polymerizations were also presented. 
Polymerization processes should also be adapted to be environmentally friendly. Thus, a process with low energy consumption (e.g. photo-induced reactions) as well as the reduction of waste and the use of safer solvents and auxiliaries is desired. Solvent-free polymerization and curing processes should be privileged. On the other hand, the use of aqueous processes such as aqueous emulsion polymerization is gaining importance due to the use of water as continuous phase and the different possible applications in coatings and adhesives of the obtained polymers.

Another aspect that should be pursued for some specific applications is the (bio)degradability of materials. The synthesis of polyesters with biobased molecules such as eugenol is an interesting line to explore. Similarly, the synthesis of materials that can be reprocessable or with self-healing properties needs to be addressed. Lately, vitrimers have caught the attention of the scientific community due to the possibility to obtain self-healing materials.

This review also aimed to provide the reader a suitable toolbox of possible reactions and polymerization examples so that researchers not only exploit them further in the design of novel eugenol-derived monomers but also in the design of other biobased molecules, especially the ones coming from lignin depolymerization. Although lignin depolymerization is not an optimized process yet, it is currently widely studied because of the large availability of this raw material. It is an opportunity to valorize the lignin-derived molecules in higher added value biobased materials and to contribute to the highly expected circular economy.

\section{ACKNOWLEDGEMENTS}

In memory of David Barucchi

\section{REFERENCES}

1. Van Schoubroeck, S.; Van Dael, M.; Van Passel, S.; Malina, R., A review of sustainability indicators for biobased chemicals. Renew. Sustain. Energy Rev. 2018, 94, 115-126.

2. Skoczinski, P.; Chinthapalli, R.; Carus, M.; Baltus, W.; Guzman, D. d.; Käb, H.; Raschka, A.; Ravenstijn, J. Bio-based Building Blocks and Polymers - Global Capacities, Production and Trends 2019 - 2024; nova-Institute: Huerth, Germany, 2019. http://biobased.eu/downloads/bio-based-building-blocks-and-polymers-global-capacities-productionand-trends-2019-2024-2/ (accessed 2020-11-18).

3. Hopewell, J.; Dvorak, R.; Kosior, E., Plastics recycling: challenges and opportunities. Philos. Trans. R. Soc. B 2009, 364, (1526), 2115-2126.

4. Corma, A.; Iborra, S.; Velty, A., Chemical Routes for the Transformation of Biomass into Chemicals. Chem. Rev. 2007, 107, (6), 2411-2502.

5. Christensen, C. H.; Rass-Hansen, J.; Marsden, C. C.; Taarning, E.; Egeblad, K., The Renewable Chemicals Industry. ChemSusChem 2008, 1, (4), 283-289.

6. Gallezot, P., Conversion of biomass to selected chemical products. Chem. Soc. Rev. 2012, 41, (4), 1538-1558. 
7. Sheldon, R. A., Green and sustainable manufacture of chemicals from biomass: state of the art. Green Chem. 2014, 16, (3), 950-963.

8. Álvarez-Chávez, C. R.; Edwards, S.; Moure-Eraso, R.; Geiser, K., Sustainability of biobased plastics: general comparative analysis and recommendations for improvement. J. Clean. Prod. 2012, 23, (1), 47-56.

9. Rudin, A.; Choi, P., Biopolymers. In The Elements of Polymer Science \& Engineering, 3rd ed.; Academic Press, 2013; pp 521-535.

10. Iwata, T., Biodegradable and Bio-Based Polymers: Future Prospects of Eco-Friendly Plastics. Angew. Chem. Int. Ed. 2015, 54, (11), 3210-3215.

11. Nakajima, H.; Dijkstra, P.; Loos, K., The Recent Developments in Biobased Polymers toward General and Engineering Applications: Polymers that are Upgraded from Biodegradable Polymers, Analogous to Petroleum-Derived Polymers, and Newly Developed. Polymers 2017, 9, (10), 523.

12. Helanto, K. E.; Matikainen, L.; Talja, R.; Rojas, O. J., Bio-based polymers for sustainable packaging and biobarriers: a critical review. BioResources 2019, 14, (2), 4902-4951.

13. Endres, H.-J., Bioplastics. In Biorefineries, 1st ed.; Springer International Publishing, 2019; 427-468.

14. Lu, J.; Tappel, R. C.; Nomura, C. T., Mini-Review: Biosynthesis of Poly(hydroxyalkanoates). Polymer Reviews 2009, 49, (3), 226-248.

15. Xia, Y.; Larock, R. C., Vegetable oil-based polymeric materials: synthesis, properties, and applications. Green Chem. 2010, 12, (11), 1893-1909.

16. Chapter 7 - Lignin-Modified Materials and Their Applications. In Lignin Chemistry and Applications, Huang, J.; Fu, S.; Gan, L., Eds. Elsevier: 2019; 181-210.

17. Thirukumaran, P.; Sathiyamoorthi, R.; Shakila Parveen, A.; Sarojadevi, M., New benzoxazines from renewable resources for green composite applications. Polym. Compos. 2016, 37, (2), 573-582.

18. Lochab, B.; Shukla, S.; Varma, I. K., Naturally occurring phenolic sources: monomers and polymers. RSC Adv. 2014, 4, (42), 21712-21752.

19. Balachandran, V. S.; Jadhav, S. R.; Vemula, P. K.; John, G., Recent advances in cardanol chemistry in a nutshell: from a nut to nanomaterials. Chem. Soc. Rev. 2013, 42, (2), 427-438.

20. Caillol, S., Cardanol: A promising building block for biobased polymers and additives. Curr. Opin. Green Sustain. Chem. 2018, 14, 26-32.

21. Raquez, J. M.; Deléglise, M.; Lacrampe, M. F.; Krawczak, P., Thermosetting (bio)materials derived from renewable resources: A critical review. Prog. Polym. Sci. 2010, 35, (4), 487-509.

22. Sahoo, S.; Misra, M.; Mohanty, A. K., Enhanced properties of lignin-based biodegradable polymer composites using injection moulding process. Compos. Part A Appl. Sci. Manuf. 2011, 42, (11), 1710-1718.

23. Sun, Z.; Fridrich, B.; de Santi, A.; Elangovan, S.; Barta, K., Bright Side of Lignin Depolymerization: Toward New Platform Chemicals. Chem. Rev. 2018, 118, (2), 614-678.

24. Decostanzi, M.; Auvergne, R.; Boutevin, B.; Caillol, S., Biobased phenol and furan derivative coupling for the synthesis of functional monomers. Green Chem. 2019, 21, (4), 724747.

25. Rais, D.; Zibek, S., Biotechnological and Biochemical Utilization of Lignin. In Biorefineries, 1st ed.; Springer International Publishing, 2019; pp 469-518.

26. Khalil, A. A.; Rahman, U. U.; Khan, M. R.; Sahar, A.; Mehmood, T.; Khan, M., Essential oil eugenol: sources, extraction techniques and nutraceutical perspectives. RSC Adv. 2017, 7, (52), 32669-32681.

27. Goh, C. S.; Lee, K. T., Second-generation biofuel (SGB) in Southeast Asia via lignocellulosic biorefinery: Penny-foolish but pound-wise. Renew. Sustain. Energy Rev. 2011, $15,(6), 2714-2718$. 
28. Sabiha-Hanim, S.; Noor, M. A. M.; Rosma, A., Effect of autohydrolysis and enzymatic treatment on oil palm (Elaeis guineensis Jacq.) frond fibres for xylose and xylooligosaccharides production. Bioresour. Technol. 2011, 102, (2), 1234-1239.

29. Goh, C. S.; Tan, H. T.; Lee, K. T., Pretreatment of oil palm frond using hot compressed water: An evaluation of compositional changes and pulp digestibility using severity factors. Bioresour. Technol. 2012, 110, 662-669.

30. Danthu, P.; Simanjuntak, R.; Fawbush, F.; Leong Pock Tsy, J. M.; Razafimamonjison, G.; Abdillahi, M. M.; Jahiel, M.; Penot, E., The clove tree and its products (clove bud, clove oil, eugenol): prosperous today but what of tomorrow's restrictions? Fruits 2020, 75, (5), 224-242. 31. The global eugenol market is expected to grow with the CAGR of $8 \%$ by 2025 . https://www.lucintel.com/press/eugenol-market.aspx (accessed 2021-06-29),

32. Anti-Microbial Properties of Eugenol to drive the Global Eugenol Market to Reach US\$ 754.1 million revenue by 2026 end. https://www.globenewswire.com/newsrelease/2018/03/07/1417672/0/en/Anti-Microbial-Properties-of-Eugenol-to-drive-the-GlobalEugenol-Market-to-Reach-US-754-1-million-revenue-by-2026-end.html (accessed 2021-06-29), 33. Kamatou, G. P.; Vermaak, I.; Viljoen, A. M., Eugenol-From the Remote Maluku Islands to the International Market Place: A Review of a Remarkable and Versatile Molecule. Molecules 2012, 17, (6), 6953-6981.

34. Raja, M. R. C.; Srinivasan, V.; Selvaraj, S.; Mahapatra, S. K., Versatile and Synergistic Potential of Eugenol: A Review. Pharm. Anal. Acta 2015, 6, (5), 367.

35. Caillol, S.; Boutevin, B.; Auvergne, R., Eugenol, a developing asset in biobased epoxy resins. Polymer 2021, 223, 123663.

36. Barceloux, D. G., Clove and Eugenol [Syzygium aromaticum (L.) Merr. \& L. M. Perry]. In Medical Toxicology of Natural Substances: foods, fungi, medicinal herbs, plants, and venomous animals, John Wiley \& Sons, Inc.: 2008; 437-442.

37. Chaieb, K.; Hajlaoui, H.; Zmantar, T.; Kahla-Nakbi, A. B.; Rouabhia, M.; Mahdouani, K.; Bakhrouf, A., The chemical composition and biological activity of clove essential oil, Eugenia caryophyllata (Syzigium aromaticum L. Myrtaceae): a short review. Phytother. Res. 2007, 21, (6), 501-506.

38. TRIDGE Clove global production. https://www.tridge.com/intelligences/clove/production (accessed 04/23/2020),

39. Nejad, S. M.; Ozgunes, H.; Basaran, N., Pharmacological and toxicological properties of eugenol. Turk. J. Pharm. Sci. 2017, 14, (2), 201-206.

40. Jeyaratnam, N.; Nour, A. H.; Kanthasamy, R.; Nour, A. H.; Yuvaraj, A. R.; Akindoyo, J. O., Essential oil from Cinnamomum cassia bark through hydrodistillation and advanced microwave assisted hydrodistillation. Ind. Crops Prod. 2016, 92, 57-66.

41. Guan, W.; Li, S.; Yan, R.; Tang, S.; Quan, C., Comparison of essential oils of clove buds extracted with supercritical carbon dioxide and other three traditional extraction methods. Food Chem. 2007, 101, (4), 1558-1564.

42. Li, Y.; Fabiano-Tixier, A.-S.; Chemat, F., Essential Oils: From Conventional to Green Extraction. In Essential Oils as Reagents in Green Chemistry, Springer International Publishing: Cham, 2014; pp 9-20.

43. Chatterjee, D.; Bhattacharjee, P., Supercritical Carbon Dioxide Extraction of Eugenol from Clove Buds. Food Bioproc. Tech. 2013, 6, (10), 2587-2599.

44. Zakzeski, J.; Bruijnincx, P. C. A.; Jongerius, A. L.; Weckhuysen, B. M., The Catalytic Valorization of Lignin for the Production of Renewable Chemicals. Chem. Rev. 2010, 110, (6), 3552-3599.

45. Nimmanwudipong, T.; Runnebaum, R. C.; Ebeler, S. E.; Block, D. E.; Gates, B. C., Upgrading of Lignin-Derived Compounds: Reactions of Eugenol Catalyzed by HY Zeolite and by $\mathrm{Pt} / \mathrm{Y}$-Al2O3. Catal. Lett. 2012, 142, (2), 151-160.

46. Isikgor, F. H.; Becer, C. R., Lignocellulosic biomass: a sustainable platform for the production of bio-based chemicals and polymers. Polym. Chem. 2015, 6, (25), 4497-4559. 
47. US Food \& Drug Administration, Code of Federal Regulations [21CFR184.1257]. Clove and its derivatives, last revised April 2020. https://www.accessdata.fda.gov/scripts/cdrh/cfdocs/cfcfr/CFRSearch.cfm?fr=184.1257 (accesed 2020-11-18).

48. Janes, S. E. J.; Price, C. S. G.; Thomas, D., Essential oil poisoning: N-acetylcysteine for eugenol-induced hepatic failure and analysis of a national database. Eur. J. Pediatr. 2005, 164, (8), 520-522.

49. Hartnoll, G.; Moore, D.; Douek, D., Near fatal ingestion of oil of cloves. Arch. Dis. Child. 1993, 69, (3), 392-393.

50. Blank, I.; Fischer, K.-H.; Grosch, W., Intensive neutral odourants of linden honey Differences from honeys of other botanical origin. Z. Lebensm. Unters. Forsch. 1989, 189, (5), 426-433.

51. Curtis, E. K., In pursuit of palliation: oil of cloves in the art of dentistry. Bull. Hist. Dent. 1990, 38, (2), 9-14.

52. Leem, H.-H.; Kim, E.-O.; Mi-Jae, S.; Choi, S.-W., Antioxidant and Anti-Inflammatory Activities of Eugenol and Its Derivatives from Clove (Eugenia caryophyllata Thunb.) 2011, 40, (10), 1361-1370.

53. Srinivasan, K., Antioxidant Potential of Spices and Their Active Constituents. Crit. Rev. Food Sci. Nutr. 2014, 54, (3), 352-372.

54. Laekeman, G. M.; van Hoof, L.; Haemers, A.; Berghe, D. A. V.; Herman, A. G.; Vlietinck, A. J., Eugenol a valuable compound for in vitro experimental research and worthwhile for further in vivo investigation. Phytother. Res. 1990, 4, (3), 90-96.

55. Ali, S. M.; Khan, A. A.; Ahmed, I.; Musaddiq, M.; Ahmed, K. S.; Polasa, H.; Rao, L. V.; Habibullah, C. M.; Sechi, L. A.; Ahmed, N., Antimicrobial activities of Eugenol and Cinnamaldehyde against the human gastric pathogen Helicobacter pylori. Ann. Clin. Microbiol. Antimicrob. 2005, 4, 20-20.

56. Chami, N.; Bennis, S.; Chami, F.; Aboussekhra, A.; Remmal, A., Study of anticandidal activity of carvacrol and eugenol in vitro and in vivo. Oral Microbiol. Immunol. 2005, 20, (2), 106-111.

57. Schmidt, E.; Jirovetz, L.; Wlcek, K.; Buchbauer, G.; Gochev, V.; Girova, T.; Stoyanova, A.; Geissler, M., Antifungal Activity of Eugenol and Various Eugenol-Containing Essential Oils against 38 Clinical Isolates of Candida albicans. J. Essent. Oil-Bear. Plants 2007, 10, (5), 421429.

58. Benencia, F.; Courrèges, M. C., In vitro and in vivo activity of eugenol on human herpesvirus. Phytother. Res. 2000, 14, (7), 495-500.

59. Tragoolpua, Y.; Jatisatienr, A., Anti-herpes simplex virus activities of Eugenia caryophyllus (Spreng.) Bullock \& S. G. Harrison and essential oil, eugenol. Phytother. Res. 2007, 21, (12), 1153-1158.

60. Daniel, A. N.; Sartoretto, S. M.; Schmidt, G.; Caparroz-Assef, S. M.; Bersani-Amado, C. A.; Cuman, R. K. N., Anti-inflammatory and antinociceptive activities A of eugenol essential oil in experimental animal models. Rev. Bras. Farmacogn. 2009, 19, 212-217.

61. Kurian, R.; Arulmozhi, D.; Veeranjaneyulu, A.; Bodhankar, S., Effect of eugenol on animal models of nociception. Indian J. Pharmacol. 2006, 38, (5), 341-345.

62. Jaganathan, S. K.; Supriyanto, E., Antiproliferative and Molecular Mechanism of Eugenol-Induced Apoptosis in Cancer Cells. Molecules 2012, 17, (6), 6290-6304.

63. Cui, Z.; Liu, Z.; Zeng, J.; Chen, L.; Wu, Q.; Mo, J.; Zhang, G.; Song, L.; Xu, W.; Zhang, S.; Guo, X., Eugenol inhibits non-small cell lung cancer by repressing expression of NF-kBregulated TRIM59. Phytother. Res. 2019, 33, (5), 1562-1569.

64. Javaheri, S.; Nekoubin, H.; Moradlu, A., Effect of anesthesia with clove oil in fish (review). Fish Physiol. Biochem. 2012, 38, 1545-1552

65. Bowker, J. D.; Trushenski, J. T.; Glover, D. C.; Carty, D. G.; Wandelear, N., Sedative options for fish research: a brief review with new data on sedation of warm-, cool-, and 
coldwater fishes and recommendations for the drug approval process. Rev. Fish Biol. Fish. 2015, 25, (1), 147-163.

66. Hoseini, S. M.; Mirghaed, A. T.; Yousefi, M., Application of herbal anaesthetics in aquaculture. Rev. Aquac. 2019, 11, (3), 550-564.

67. Ogata, M.; Hoshi, M.; Urano, S.; Endo, T., Antioxidant Activity of Eugenol and Related Monomeric and Dimeric Compounds. Chem. Pharm. Bull. 2000, 48, (10), 1467-1469.

68. da Silva, F. F. M.; Monte, F. J. Q.; de Lemos, T. L. G.; do Nascimento, P. G. G.; de Medeiros Costa, A. K.; de Paiva, L. M. M., Eugenol derivatives: synthesis, characterization, and evaluation of antibacterial and antioxidant activities. Chem. Cent. J. 2018, 12, (1), 34.

69. Pramod, K.; Ansari, S. H.; Ali, J., Eugenol: A Natural Compound with Versatile Pharmacological Actions. Nat. Prod. Commun. 2010, 5, (12), 1934578X1000501236.

70. Yalkowsky, S. H.; He, Y.; Jain, P., Handbook of Aqueous Solubility Data. Taylor \& Francis Group: 2010.

71. Wassermann, M., Ueber die relative Constitution des Eugenols. Justus Liebigs Ann. Chem. 1875, 179, (3), 366-388.

72. Hoyle, C. E.; Bowman, C. N., Thiol-Ene Click Chemistry. Angew. Chem. Int. Ed. 2010, 49, (9), 1540-1573.

73. Heo, J.; Kang, T.; Jang, S. G.; Hwang, D. S.; Spruell, J. M.; Killops, K. L.; Waite, J. H.; Hawker, C. J., Improved Performance of Protected Catecholic Polysiloxanes for Bioinspired Wet Adhesion to Surface Oxides. J. Am. Chem. Soc. 2012, 134, (49), 20139-20145.

74. Watanabe, H.; Takahashi, M.; Kihara, H.; Yoshida, M., Biobased Coatings Based on Eugenol Derivatives. ACS Appl. Bio Mater. 2018, 1, (3), 808-813.

75. Lenardão, E. J.; Jacob, R. G.; Mesquita, K. D.; Lara, R. G.; Webber, R.; Martinez, D. M.; Savegnago, L.; Mendes, S. R.; Alves, D.; Perin, G., Glycerol as a promoting and recyclable medium for catalyst-free synthesis of linear thioethers: new antioxidants from eugenol. Green Chem. Lett. Rev. 2013, 6, (4), 269-276.

76. Hu, K. L.; Zhao, D. P.; Wu, G. L.; Ma, J. B., Polyesters derived from bio-based eugenol and 10-undecenoic acid: synthesis, characterization, and structure-property relationships. RSC Adv. 2015, 5, (105), 85996-86005.

77. Hu, Y.; Tian, Y.; Cheng, J.; Zhang, J., Synthesis of Eugenol-Based Polyols via Thiol-Ene Click Reaction and High-Performance Thermosetting Polyurethane Therefrom. ACS Sustain. Chem. Eng. 2020, 8, (10), 4158-4166.

78. Tian, Y.; Wang, Q.; Hu, Y.; Sun, H.; Cui, Z.; Kou, L.; Cheng, J.; Zhang, J., Preparation and shape memory properties of rigid-flexible integrated epoxy resins via tunable micro-phase separation structures. Polymer 2019, 178, 121592.

79. Hu, K. L.; Zhao, D. P.; Wu, G. L.; Ma, J. B., Toughened aromatic poly-(decylene terephthalate) copolyesters with two renewable eugenol-based components via a random copolymerization method. Polym. Chem. 2016, 7, (5), 1096-1110.

80. Dai, J. Y.; Jiang, Y. H.; Liu, X. Q.; Wang, J. G.; Zhu, J., Synthesis of eugenol-based multifunctional monomers via a thiol-ene reaction and preparation of UV curable resins together with soybean oil derivatives. RSC Adv. 2016, 6, (22), 17857-17866.

81. Chapala, P. P.; Bermeshev, M. V.; Korchagina, S. A.; Ashirov, R. V.; Bermesheva, E. V., Synthesis of 3,4-dihydroxyphenyl-containing polymeric materials from 1,2-polybutadiene and eugenol via thiol-ene addition. Russ. Chem. Bull. 2016, 65, (4), 1061-1066.

82. Bermesheva, E. V.; Chapala, P. P.; Bermeshev, M. V., A new approach to the synthesis of polymers bearing 3,4-dihydroxyphenyl-moieties in side groups from eugenol and polybutadiene with help of thiol-ene reaction. AIP Conf. Proc. 2018, 1981, (1), 020178.

83. Montagut, A. M.; Granados, A.; Ballesteros, A.; Pleixats, R.; Llagostera, M.; Cortés, P.; Sebastián, R. M.; Vallribera, A., Antibiotic protected silver nanoparticles for microbicidal cotton. Tetrahedron 2019, 75, (1), 102-108. 
84. Hu, K.; Wu, G.; Ma, J., Aromatic copolyesters with enhanced crystallizability and mechanical properties by adding the renewable nipagin-based composition. RSC Adv. 2016, 6, (26), 21555-21563.

85. Shrestha, M. L.; Ionescu, M., Aliphatic-Aromatic Polyols by Thiol-Ene Reactions. J. Polym. Environ. 2018, 26, (6), 2257-2267.

86. Miao, J.-T.; Yuan, L.; Guan, Q.; Liang, G.; Gu, A., Biobased Heat Resistant Epoxy Resin with Extremely High Biomass Content from 2,5-Furandicarboxylic Acid and Eugenol. ACS Sustain. Chem. Eng. 2017, 5, (8), 7003-7011.

87. Wan, J.; Zhao, J.; Gan, B.; Li, C.; Molina-Aldareguia, J.; Zhao, Y.; Pan, Y.-T.; Wang, D.-Y., Ultrastiff Biobased Epoxy Resin with High Tg and Low Permittivity: From Synthesis to Properties. ACS Sustain. Chem. Eng. 2016, 4, (5), 2869-2880.

88. Faye, I.; Decostanzi, M.; Ecochard, Y.; Caillol, S., Eugenol bio-based epoxy thermosets: from cloves to applied materials. Green Chem. 2017, 19, (21), 5236-5242.

89. Cheng, C. J.; Li, Y. P.; Zhang, X.; Li, J., Eugenol-based non-isocyanate polyurethane and polythiourethane. Iran. Polym. J. 2017, 26, (11), 821-831.

90. Alhaffar, M. T.; Akhtar, M. N.; Ali, S. A., Utilization of catecholic functionality in natural safrole and eugenol to synthesize mussel-inspired polymers. RSC Adv. 2019, 9, (37), 2126521277.

91. Guzman, D.; Serra, A.; Ramis, X.; Fernandez-Francos, X.; De la Flor, S., Fully renewable thermosets based on bis-eugenol prepared by thiol-click chemistry. React. Funct. Polym. 2019, 136, 153-166.

92. Hutchinson, S. A.; Luetjens, H.; Scammells, P. J., A new synthesis of the benzofuran adenosine antagonist XH-14. Bioorg. Med. Chem. Lett. 1997, 7, (24), 3081-3084.

93. García-Muñoz, S.; Jiménez-González, L.; Álvarez-Corral, M.; Muñoz-Dorado, M.; Rodríguez-García, I., Benzo[f][1,2]oxasilepines in the Synthesis of Dihydro[b]benzofuran Neolignans. Synlett 2005, 2005, (19), 3011-3013.

94. Pepper, J. M.; Sundaram, G. S.; Dyson, G., Lignin and Related Compounds. III. An Improved Synthesis of 3-(4-Hydroxy-3-methoxyphenyl)-1-propanol and 3-(4-Hydroxy-3,5dimethoxyphenyl)-1-propanol. Can. J. Chem. 1971, 49, (20), 3394-3395.

95. Hemelaere, R.; Carreaux, F.; Carboni, B., A Diastereoselective Route to trans-2-Aryl-2,3dihydrobenzofurans through Sequential Cross-Metathesis/Isomerization/Allylboration Reactions: Synthesis of Bioactive Neolignans. Eur. J. Org. Chem. 2015, 2015, (11), 2470-2481.

96. Dalko, M.; Hitce, J. Novel 1-Phenylmono- or -Polyhydroxypropane Compounds, Compositions and Cosmetic Uses Thereof. WO2016092074 (A1), 2016.

97. Eey, S. T. C.; Lear, M. J., A Bismuth(III)-Catalyzed Friedel-Crafts Cyclization and Stereocontrolled Organocatalytic Approach to (-)-Platensimycin. Org. Lett. 2010, 12, (23), 5510-5513.

98. Yadav, Y.; Owens, E. A.; Sharma, V.; Aneja, R.; Henary, M., Synthesis and evaluation of antiproliferative activity of a novel series of hydroxychavicol analogs. Eur. J. Med. Chem. 2014, 75, 1-10.

99. Chen, G.; Feng, J.; Qiu, W.; Zhao, Y., Eugenol-modified polysiloxanes as effective anticorrosion additives for epoxy resin coatings. RSC Adv. 2017, 7, (88), 55967-55976.

100. Ji, J.; Ge, X.; Liang, W.; Liang, R.; Pang, X.; Liu, R.; Wen, S.; Sun, J.; Chen, X.; Ge, J., A Simple Preparation Route for Bio-Phenol MQ Silicone Resin via the Hydrosilylation Method and its Autonomic Antibacterial Property. Polymers 2019, 11, (9), 1389.

101. Yi, M.; Chen, X.; Shuttleworth, P. S.; Tan, L.; Ruan, Y.; Xu, Y.; Zheng, J.; Wu, S.; Hu, S.; Xie, S.; Guan, Z.; Yin, G.; Cui, Y., Facile fabrication of eugenol-containing polysiloxane films with good optical properties and excellent thermal stability via $\mathrm{Si}-\mathrm{H}$ chemistry. J. Mater. Chem. $\mathrm{C}$ 2021, 9, (25), 8020-8028.

102. Zhang, X.; Cai, Y.; Zhang, X.; Aziz, T.; Fan, H.; Bittencourt, C., Synthesis and characterization of eugenol-based silicone modified waterborne polyurethane with excellent properties. J. Appl. Polym. Sci. 2021, 138, (22), 50515. 
103. Blackwell, H. E.; O'Leary, D. J.; Chatterjee, A. K.; Washenfelder, R. A.; Bussmann, D. A.; Grubbs, R. H., New Approaches to Olefin Cross-Metathesis. J. Am. Chem. Soc. 2000, 122, (1), 58-71.

104. Taber, D. F.; Frankowski, K. J., Grubbs's Cross Metathesis of Eugenol with cis-2-Butene1,4-diol To Make a Natural Product. An Organometallic Experiment for the Undergraduate Lab. J. Chem. Educ. 2006, 83, (2), 283.

105. Brett Runge, M.; Mwangi, M. T.; Bowden, N. B., New selectivities from old catalysts. Occlusion of Grubbs' catalysts in PDMS to change their reactions. J. Organomet. Chem. 2006, 691, (24), 5278-5288.

106. Harvey, B. G.; Sahagun, C. M.; Guenthner, A. J.; Groshens, T. J.; Cambrea, L. R.; Reams, J. T.; Mabry, J. M., A High-Performance Renewable Thermosetting Resin Derived from Eugenol. ChemSusChem 2014, 7, (7), 1964-1969.

107. Trita, A. S.; Over, L. C.; Pollini, J.; Baader, S.; Riegsinger, S.; Meier, M. A. R.; Goossen, L. J., Synthesis of potential bisphenol A substitutes by isomerising metathesis of renewable raw materials. Green Chem. 2017, 19, (13), 3051-3060.

108. Zago, E.; Dubreucq, E.; Lecomte, J.; Villeneuve, P.; Fine, F.; Fulcrand, H.; Aouf, C., Synthesis of bio-based epoxy monomers from natural allyl- and vinyl phenols and the estimation of their affinity to the estrogen receptor $\alpha$ by molecular docking. New J. Chem. 2016, 40, (9), 7701-7710.

109. Chittimalla, S. K.; Bandi, C.; Putturu, S.; Kuppusamy, R.; Boellaard, K. C.; Tan, D. C. A.; Lum, D. M. J., Access to 3-Arylindoles through a Tandem One-Pot Protocol Involving Dearomatization, a Regioselective Michael Addition Reaction, and Rearomatization. Eur. J. Org. Chem. 2014, 2014, (12), 2565-2575.

110. Peterson, T. H.; Bryan, J. H.; Keevil, T. A., A kinetic study of the isomerization of eugenol: The quantitative use of NMR, GC, and HPLC in a single organic laboratory experiment that demonstrates alternative approaches to solving a problem. J. Chem. Educ. 1993, 70, (4), A96.

111. Kishore, D.; Kannan, S., Isomerization of eugenol and safrole over MgAl hydrotalcite, a solid base catalyst. Green Chem. 2002, 4, (6), 607-610.

112. Neda, M.; Okinaga, K.; Shibata, M., High-performance bio-based thermosetting resins based on bismaleimide and allyl-etherified eugenol derivatives. Mater. Chem. Phys. 2014, 148, (1), 319-327.

113. Shibata, M.; Shimasaki, T.; Satoh, H.; Iwai, M.; Neda, M., Bio-based thermosetting resins composed of aliphatic polyol-derived polymaleimides and allyleugenol. React. Funct. Polym. 2015, 97, 69-76.

114. Yoshimura, T.; Shimasaki, T.; Teramoto, N.; Shibata, M., Bio-based polymer networks by thiol-ene photopolymerizations of allyl-etherified eugenol derivatives. Eur. Polym. J. 2015, 67, 397-408.

115. Guzmán, D.; Mateu, B.; Fernández-Francos, X.; Ramis, X.; Serra, A., Novel thermal curing of cycloaliphatic resins by thiol-epoxy click process with several multifunctional thiols. Polym. Int. 2017, 66, (12), 1697-1707.

116. Guzmán, D.; Ramis, X.; Fernández-Francos, X.; De la Flor, S.; Serra, A., Preparation of new biobased coatings from a triglycidyl eugenol derivative through thiol-epoxy click reaction. Prog. Org. Coat. 2018, 114, 259-267.

117. Yu, A. Z.; Serum, E. M.; Renner, A. C.; Sahouani, J. M.; Sibi, M. P.; Webster, D. C., Renewable Reactive Diluents as Practical Styrene Replacements in Biobased Vinyl Ester Thermosets. ACS Sustain. Chem. Eng. 2018, 6, (10), 12586-12592.

118. Jiang, T.-S.; Zhang, Q.; Li, G.; Cheng, X.; Cai, Y., DDQ-Mediated Oxidation of Allylarenes: Expedient Access to Cinnamaldehyde-Containing Phenylpropanoids. Synthesis 2018, 50, (23), 4611-4616. 
119. Dai, J. Y.; Ma, S. Q.; Zhu, L. X.; Wang, S.; Yang, L. J.; Song, Z. L.; Liu, X. Q.; Zhu, J., UVthermal dual cured anti-bacterial thiol-ene networks with superior performance from renewable resources. Polymer 2017, 108, 215-222.

120. Modjinou, T.; Rodriguez-Tobias, H.; Morales, G.; Versace, D. L.; Langlois, V.; Grande, D.; Renard, E., UV-cured thiol-ene eugenol/ZnO composite materials with antibacterial properties. RSC Adv. 2016, 6, (91), 88135-88142.

121. Modjinou, T.; Versace, D. L.; Abbad-Andallousi, S.; Bousserrhine, N.; Dubot, P.; Langlois, V.; Renard, E., Antibacterial and antioxidant bio-based networks derived from eugenol using photo-activated thiol-ene reaction. React. Funct. Polym. 2016, 101, 47-53.

122. Glaive, A. S.; Modjinou, T.; Versace, D. L.; Abbad-Andaloussi, S.; Dubot, P.; Langlois, V.; Renard, E., Design of Antibacterial and Sustainable Antioxidant Networks Based on Plant Phenolic Derivatives Used As Delivery System of Carvacrol or Tannic Acid. ACS Sustain. Chem. Eng. 2017, 5, (3), 2320-2329.

123. Rios de Anda, A.; Sotta, P.; Modjinou, T.; Langlois, V.; Versace, D.-L.; Renard, E., Multiscale Structural Characterization of Biobased Diallyl-Eugenol Polymer Networks. Macromolecules 2020, 53, (6), 2187-2197.

124. Cheng, C. J.; Zhang, X.; Chen, X. H.; Li, J.; Huang, Q. H.; Hu, Z. Y.; Tu, Y. M., Self-healing polymers based on eugenol via combination of thiol-ene and thiol oxidation reactions. J. Polym. Res. 2016, 23, 110.

125. Llevot, A.; Monney, B.; Sehlinger, A.; Behrens, S.; Meier, M. A. R., Highly efficient TsujiTrost allylation in water catalyzed by Pd-nanoparticles. Chem. Commun. 2017, 53, (37), 51755178.

126. Tsuji, J.; Takahashi, H.; Morikawa, M., Organic syntheses by means of noble metal compounds XVII. Reaction of $\pi$-allylpalladium chloride with nucleophiles. Tetrahedron Lett. 1965, 6, (49), 4387-4388.

127. Trost, B. M.; Fullerton, T. J., New synthetic reactions. Allylic alkylation. J. Am. Chem. Soc. 1973, 95, (1), 292-294.

128. Charan Raja, M. R.; Velappan, A. B.; Chellappan, D.; Debnath, J.; Kar Mahapatra, S., Eugenol derived immunomodulatory molecules against visceral leishmaniasis. Eur. J. Med. Chem. 2017, 139, 503-518.

129. Maiorana, A.; Yue, L.; Manas-Zloczower, I.; Gross, R., Structure-property relationships of a bio-based reactive diluent in a bio-based epoxy resin. J. Appl. Polym. Sci. 2016, 133, 43635

130. Shibata, M.; Sugane, K.; Satoh, A., Photo-thermally cured eugenol-derived epoxy resins by simultaneous thiol-ene/thiol-epoxy/thiol-maleimide triple "click" reactions. J. Polym. Res. 2018, 25, 234.

131. Ecochard, Y.; Leroux, J.; Boutevin, B.; Auvergne, R.; Caillol, S., From multi-functional siloxane-based cyclic carbonates to hybrid polyhydroxyurethane thermosets. Eur. Polym. J. 2019, 120, 109280.

132. Genç Bilgiçli, H.; Kestane, A.; Taslimi, P.; Karabay, O.; Bytyqi-Damoni, A.; Zengin, M.; Gulçin, i., Novel eugenol bearing oxypropanolamines: Synthesis, characterization, antibacterial, antidiabetic, and anticholinergic potentials. Bioorg. Chem. 2019, 88, 102931.

133. Modjinou, T.; Versace, D.-L.; Abbad-Andaloussi, S.; Langlois, V.; Renard, E., Enhancement of Biological Properties of Photoinduced Biobased Networks by PostFunctionalization with Antibacterial Molecule. ACS Sustain. Chem. Eng. 2019, 7, (2), 2500-2507. 134. Rojo, L.; Vazquez, B.; Parra, J.; López Bravo, A.; Deb, S.; San Roman, J., From Natural Products to Polymeric Derivatives of "Eugenol": A New Approach for Preparation of Dental Composites and Orthopedic Bone Cements. Biomacromolecules 2006, 7, (10), 2751-2761.

135. Molina-Gutiérrez, S.; Manseri, A.; Ladmiral, V.; Bongiovanni, R.; Caillol, S.; LacroixDesmazes, P., Eugenol: A Promising Building Block for Synthesis of Radically Polymerizable Monomers. Macromol. Chem. Phys. 2019, 220, (14), 1900179. 
136. Molina-Gutiérrez, S.; Ladmiral, V.; Bongiovanni, R.; Caillol, S.; Lacroix-Desmazes, P., Emulsion Polymerization of Dihydroeugenol-, Eugenol-, and Isoeugenol-Derived Methacrylates. Ind. Eng. Chem. Res. 2019, 58, (46), 21155-21164.

137. Wang, X.; Yi, M.; Du, Q.; Wu, A.; Xiao, R., Design and synthesis of novel pyrethriods containing eugenol moiety. Med. Chem. Res. 2012, 21, (10), 2827-2830.

138. Satoh, K.; Saitoh, S.; Kamigaito, M., A Linear Lignin Analogue: Phenolic Alternating Copolymers from Naturally Occurring $\beta$-Methylstyrene via Aqueous-Controlled Cationic Copolymerization. J. Am. Chem. Soc. 2007, 129, (31), 9586-9587.

139. Rojo, L.; Borzacchiello, A.; Parra, J.; Deb, S.; Vázquez, B.; San Román, J., The preparation of high conversion polymeric systems containing eugenol residues and their rheological characterization. J. Mater. Sci.: Mater. Med. 2008, 19, (4), 1467-1477.

140. Lipscomb, C. E.; Lewandowski, K. M. Allyl Acrylate Crosslinkers for Psas. WO2016040773 (A1), 2016.

141. Xavier, F. J. S.; Rodrigues, K. A. d. F.; De Oliveira, R. G.; Lima Junior, C. G.; Rocha, J. D. C.; Keesen, T. S. L.; De Oliveira, M. R.; Silva, F. P. L.; Vasconcellos, M. L. A. d. A., Synthesis and In Vitro Anti Leishmania amazonensis Biological Screening of Morita-Baylis-Hillman Adducts Prepared from Eugenol, Thymol and Carvacrol. Molecules 2016, 21, (11), 1483.

142. Ding, R.; Du, Y. Y.; Goncalves, R. B.; Francis, L. F.; Reineke, T. M., Sustainable near UVcurable acrylates based on natural phenolics for stereolithography 3D printing. Polym. Chem. 2019, 10, (9), 1067-1077.

143. Pouységu, L.; Sylla, T.; Garnier, T.; Rojas, L. B.; Charris, J.; Deffieux, D.; Quideau, S., Hypervalent iodine-mediated oxygenative phenol dearomatization reactions. Tetrahedron 2010, 66, (31), 5908-5917.

144. Sang, D.; Yao, M.; Tian, J.; Chen, X.; Li, L.; Zhan, H.; You, L., Pyridine Improves Aluminum Triiodide Induced Selective Cleavage of Alkyl o-Hydroxyphenyl Ethers: A Practical and Efficient Procedure for the Preparation of Hydroxychavicol by Demethyl-ation of Eugenol. Synlett 2017, 28, (01), 138-142.

145. Sang, D.; Tu, X.; Tian, J.; He, Z.; Yao, M., Anchimerically Assisted Cleavage of Aryl Methyl Ethers by Aluminum Chloride-Sodium lodide in Acetonitrile. ChemistrySelect 2018, 3, (35), 10103-10107.

146. Sudarma, I. M.; Hizmi, S.; Darmayanti, M. G., Competitive reaction of -OH and -NH2 functional groups on synthesis of bioactive ortho-cetamol derivative (4-allyl-2-methoxy- $\mathrm{N}$ acetyl-o-aminophenol) from amino-eugenol. Asian J. Chem. 2015, 27, (10), 3887-3890.

147. Heredia, D. A.; Larghi, E. L.; Kaufman, T. S., A Straightforward Synthesis of 5Methylaaptamine from Eugenol, Employing a $6 \pi$-Electrocyclization Reaction of a 1-Azatriene. Eur. J. Org. Chem. 2016, 2016, (7), 1397-1404.

148. Sudarma, I. M.; Shahab, A.; Azim, M.; Putri, I. K.; Darmayanti, M. G., One-pot synthesis of 5-allyl-8-hydroxy-7-methoxy-2-methylquinoline. Asian J. Chem. 2016, 28, (8), 1799-1801.

149. Sudarma, I. M.; Satriani, A. R.; Darmayanti, M. G., N,N-dimethylation of nitro-eugenol to its new 4-allyl-2-(dimethylamino)-6-methoxyphenol via Eschweiler-Clarke methylation reaction. Asian J. Chem. 2017, 29, (4), 867-869.

150. Azevedo-Barbosa, H.; Ferreira-Silva, G. Á.; Silva, C. F.; de Souza, T. B.; Dias, D. F.; de Paula, A. C. C.; lonta, M.; Carvalho, D. T., Phenylpropanoid-based sulfonamide promotes cyclin $\mathrm{D} 1$ and cyclin $\mathrm{E}$ down-regulation and induces cell cycle arrest at G1/S transition in estrogen positive MCF-7 cell line. Toxicol. In Vitro 2019, 59, 150-160.

151. Weselsky, P.; Benedikt, R., Über einige Nitroproducte aus der Reihe des Brenzcatechins. Monatsh. Chem. 1882, 3, (1), 386-393.

152. Egorov, M.; Delpech, B.; Aubert, G.; Cresteil, T.; Garcia-Alvarez, M. C.; Collin, P.; Marazano, $\mathrm{C}$., A concise formation of $\mathrm{N}$-substituted 3,4-diarylpyrroles - synthesis and cytotoxic activity. Org. Biomol. Chem. 2014, 12, (9), 1518-1524.

153. Sudarma, I. M.; Wazni, N.; Wildawaty, N.; Yuanita, E.; Suana, I. W., An efficient method on nitration of eugenol using $\mathrm{NH}_{4} \mathrm{NO}_{3}$ and $\mathrm{KHSO}_{4}$. Asian J. Chem. 2014, 26, (1), 173-175. 
154. Clemo, G. R.; Turnbull, J. H., 398. The nitration of some derivatives of eugenol. J. Chem. Soc. 1949, (0), 1870-1871.

155. Carrasco, H.; Raimondi, M.; Svetaz, L.; Liberto, M. D.; Rodriguez, M. V.; Espinoza, L.; Madrid, A.; Zacchino, S., Antifungal Activity of Eugenol Analogues. Influence of Different Substituents and Studies on Mechanism of Action. Molecules 2012, 17, (1), 1002-1024.

156. Cousin, H.; Herissey, H., Oxidation of Eugenol by the Oxidizing Ferment of Mushrooms and by Ferric Chloride. Production of Dehydrodieugenol. J. Pharm. Chim. 1908, 28, 49-55.

157. de Farias Dias, A., An improved high yield synthesis of dehydrodieugenol. Phytochemistry 1988, 27, (9), 3008-3009.

158. Shibata, M.; Tetramoto, N.; Imada, A.; Neda, M.; Sugimoto, S., Bio-based thermosetting bismaleimide resins using eugenol, bieugenol and eugenol novolac. React. Funct. Polym. 2013, 73, (8), 1086-1095.

159. Li, Y.; Luo, F.; Cheng, C., Preparation of eugenol-based polyurethane. IOP Conf. Ser. Mater. Sci. Eng. 2018, 322, 022030.

160. Ogata, M.; Tutumimoto Sato, K.; Kunikane, T.; Oka, K.; Seki, M.; Urano, S.; Hiramatsu, K.; Endo, T., Antibacterial Activity of Dipropofol and Related Compounds. Biol. Pharm. Bull. 2005, 28, (6), 1120-1122.

161. Fujisawa, S.; Kashiwagi, Y.; Atsumi, T.; Iwakura, I.; Ueha, T.; Hibino, Y.; Yokoe, I., Application of bis-eugenol to a zinc oxide eugenol cement. J. Dent. 1999, 27, (4), 291-295.

162. Marques, F. A.; Simonelli, F.; Oliveira, A. R. M.; Gohr, G. L.; Leal, P. C., Oxidative coupling of 4-substituted 2-methoxy phenols using methyltributylammonium permanganate in dichloromethane. Tetrahedron Lett. 1998, 39, (9), 943-946.

163. Bouhlel, C.; Dolhem, G. A.; Fernandez, X.; Antoniotti, S., Model Study of the Enzymatic Modification of Natural Extracts: Peroxidase-Based Removal of Eugenol from Rose Essential Oil. J. Agric. Food. Chem. 2012, 60, (4), 1052-1058.

164. Llevot, A.; Grau, E.; Carlotti, S.; Grelier, S.; Cramail, H., ADMET polymerization of biobased biphenyl compounds. Polym. Chem. 2015, 6, (44), 7693-7700.

165. De Kruijff, G. H. M.; Goschler, T.; Beiser, N.; Stenglein, A.; Türk, O. M.; Waldvogel, S. R., Sustainable access to biobased biphenol epoxy resins by electrochemical dehydrogenative dimerization of eugenol. Green Chem. 2019, 21, (17), 4815-4823.

166. Alinejad, M.; Henry, C.; Nikafshar, S.; Gondaliya, A.; Bagheri, S.; Chen, N.; Singh, S. K.; Hodge, D. B.; Nejad, M., Lignin-Based Polyurethanes: Opportunities for Bio-Based Foams, Elastomers, Coatings and Adhesives. Polymers 2019, 11, (7), 1202.

167. Akindoyo, J. O.; Beg, M. D. H.; Ghazali, S.; Islam, M. R.; Jeyaratnam, N.; Yuvaraj, A. R., Polyurethane types, synthesis and applications - a review. RSC Adv. 2016, 6, (115), 114453114482.

168. Noreen, A.; Zia, K. M.; Zuber, M.; Tabasum, S.; Zahoor, A. F., Bio-based polyurethane: An efficient and environment friendly coating systems: A review. Prog. Org. Coat. 2016, 91, 2532.

169. Liang, J.-Y.; Shin, S.-R.; Lee, S.-H.; Lee, D.-S., Characteristics of Self-Healable Copolymers of Styrene and Eugenol Terminated Polyurethane Prepolymer. Polymers 2019, 11, (10), 1674.

170. Cheng, C.; Li, J.; Yang, F.; Li, Y.; Hu, Z.; Wang, J., Renewable eugenol-based functional polymers with self-healing and high temperature resistance properties. J. Polym. Res. 2018, 25, (2), 57.

171. Kathalewar, M. S.; Joshi, P. B.; Sabnis, A. S.; Malshe, V. C., Non-isocyanate polyurethanes: from chemistry to applications. RSC Adv. 2013, 3, (13), 4110-4129.

172. Maisonneuve, L.; Lamarzelle, O.; Rix, E.; Grau, E.; Cramail, H., Isocyanate-Free Routes to Polyurethanes and Poly(hydroxy Urethane)s. Chem. Rev. 2015, 115, (22), 12407-12439.

173. Cheng, C. J.; Li, J.; Yang, F. H.; Li, Y. P.; Hu, Z. Y.; Wang, J. L., Renewable eugenol-based functional polymers with self-healing and high temperature resistance properties. J. Polym. Res. 2018, 25, 57 
174. Donovan, B. R.; Cobb, J. S.; Hoff, E. F. T.; Patton, D. L., Thiol-ene adhesives from clove oil derivatives. RSC Adv. 2014, 4, (106), 61927-61935.

175. Miao, J. T.; Yuan, L.; Guan, Q. B.; Liang, G. Z.; Gu, A. J., Water-Phase Synthesis of a Biobased Allyl Compound for Building UV-Curable Flexible Thiol Ene Polymer Networks with High Mechanical Strength and Transparency. ACS Sustain. Chem. Eng. 2018, 6, (6), 7902-7909.

176. Guzmán, D.; Ramis, X.; Fernández-Francos, X.; De la Flor, S.; Serra, A., New bio-based materials obtained by thiol-ene/thiol-epoxy dual curing click procedures from eugenol derivates. Eur. Polym. J. 2017, 93, 530-544.

177. Auvergne, R.; Caillol, S.; David, G.; Boutevin, B.; Pascault, J.-P., Biobased Thermosetting Epoxy: Present and Future. Chem. Rev. 2014, 114, (2), 1082-1115.

178. Caillol, S.; Boutevin, B.; Pascault, J.-P., Bio-Sourced Epoxy Monomers and Polymers. In Handbook of Adhesive Technology, $1^{\text {st }}$ Ed.; CRC Press, 2017; pp 443-470.

179. Qin, J.; Liu, H.; Zhang, P.; Wolcott, M.; Zhang, J., Use of eugenol and rosin as feedstocks for biobased epoxy resins and study of curing and performance properties. Polym. Int. 2014, 63, (4), 760-765.

180. Wan, J.; Gan, B.; Li, C.; Molina-Aldareguia, J.; Li, Z.; Wang, X.; Wang, D.-Y., A novel biobased epoxy resin with high mechanical stiffness and low flammability: synthesis, characterization and properties. J. Mater. Chem. A 2015, 3, (43), 21907-21921.

181. Wan, J.; Gan, B.; Li, C.; Molina-Aldareguia, J.; Kalali, E. N.; Wang, X.; Wang, D.-Y., A sustainable, eugenol-derived epoxy resin with high biobased content, modulus, hardness and low flammability: Synthesis, curing kinetics and structure-property relationship. Chem. Eng. J. 2016, 284, 1080-1093.

182. Lu, S.-Y.; Hamerton, I., Recent developments in the chemistry of halogen-free flame retardant polymers. Prog. Polym. Sci. 2002, 27, (8), 1661-1712.

183. Green, J., A Review of Phosphorus- Containing Flame Retardants. J. Fire Sci. 1996, 14, (5), 353-366.

184. Decostanzi, M.; Tavernier, R.; Fontaine, G.; Bourbigot, S.; Negrell, C.; Caillol, S., Eugenol-based thermally stable thermosets by Alder-ene reaction: From synthesis to thermal degradation. Eur. Polym. J. 2019, 117, 337-346.

185. Alder, K.; Pascher, F.; Schmitz, A., Substituting additions. I. Addition of maleic anhydride and azodicarboxylic esters to singly unsaturated hydrocarbons. Substitution processes in the allyl position. Ber. Dtsch. Chem. Ges. B 1943, 76B, 27-53.

186. Hoffmann, H. M. R., The Ene Reaction. Angew. Chem., Int. Ed. Engl. 1969, 8, (8), 556-

577.

187. Iredale, R. J.; Ward, C.; Hamerton, I., Modern advances in bismaleimide resin technology: A 21st century perspective on the chemistry of addition polyimides. Prog. Polym. Sci. 2017, 69, 1-21.

188. Gaina, V.; Gaina, C., AB monomers: II, synthesis and polymerization of AB monomers containing citracon- or maleimide and allylphenyl groups. Des. Monomers Polym. 2007, 10, (1), 91-104.

189. Shibata, M.; Teramoto, N.; Shimasaki, T.; Ogihara, M., High-performance bio-based bismaleimide resins using succinic acid and eugenol. Polym. J. 2011, 43, (11), 916-922.

190. Dumas, L.; Bonnaud, L.; Olivier, M.; Poorteman, M.; Dubois, P., Bio-based high performance thermosets: Stabilization and reinforcement of eugenol-based benzoxazine networks with BMI and CNT. Eur. Polym. J. 2015, 67, 494-502.

191. Santhosh Kumar, K. S.; Reghunadhan Nair, C. P.; Sadhana, R.; Ninan, K. N., Benzoxazine-bismaleimide blends: Curing and thermal properties. Eur. Polym. J. 2007, 43, (12), 5084-5096.

192. Zhang, X. F.; Akram, R.; Zhang, S. K.; Ma, H. L.; Wu, Z. P.; Wu, D. Z., Hexa(eugenol)cyclotriphosphazene modified bismaleimide resins with unique thermal stability and flame retardancy. React. Funct. Polym. 2017, 113, 77-84. 
193. Liu, T.; Sun, L. C.; Ou, R. X.; Fan, Q.; Li, L. P.; Guo, C. G.; Liu, Z. Z.; Wang, Q. W., Flame retardant eugenol-based thiol-ene polymer networks with high mechanical strength and transparency. Chem. Eng. J. 2019, 368, 359-368.

194. Monisha, M.; Permude, P.; Ghosh, A.; Kumar, A.; Zafar, S.; Mitra, S.; Lochab, B., Halogen-free flame-retardant sulfur copolymers with stable Li-S battery performance. Energy Stor. Mater. 2020, 29, 350-360.

195. Appavoo, D.; Amarnath, N.; Lochab, B., Cardanol and Eugenol Sourced Sustainable Non-halogen Flame Retardants for Enhanced Stability of Renewable Polybenzoxazines. Front. Chem. 2020, 8, 711.

196. Ishida, H., Chapter 1 - Overview and Historical Background of Polybenzoxazine Research. In Handbook of Benzoxazine Resins, $1^{\text {st }}$ Ed.; Elsevier, 2011; pp 3-81.

197. Lligadas, G.; Tüzün, A.; Ronda, J. C.; Galià, M.; Cádiz, V., Polybenzoxazines: new players in the bio-based polymer arena. Polym. Chem. 2014, 5, (23), 6636-6644.

198. Thirukumaran, P.; Shakilaparveen, A.; Sarojadevi, M., Chapter 27 - Eugenol-Based Polybenzoxazines. In Advanced and Emerging Polybenzoxazine Science and Technology, $1^{\text {st }}$ Ed.; Elsevier, 2017; 523-531.

199. Dumas, L.; Bonnaud, L.; Olivier, M.; Poorteman, M.; Dubois, P., Eugenol-based benzoxazine: from straight synthesis to taming of the network properties. J. Mater. Chem. A 2015, 3, (11), 6012-6018.

200. Thirukumaran, P.; Shakila, A.; Muthusamy, S., Synthesis and characterization of novel bio-based benzoxazines from eugenol. RSC Adv. 2014, 4, (16), 7959-7966.

201. Thirukumaran, P.; Shakila Parveen, A.; Atchudan, R.; Kim, S.-C., Sustainability and antimicrobial assessments of bio based polybenzoxazine film. Eur. Polym. J. 2018, 109, 248256.

202. Thirukumaran, P.; Parveen, A. S.; Mani, S.; Seong-Cheol, K., Development of sustainable and antimicrobial film based on polybenzoxazine and cellulose. Int. J. Biol. Macromol. 2021, 170, 664-673.

203. Thirukumaran, P.; Shakila Parveen, A.; Sarojadevi, M., Synthesis and Copolymerization of Fully Biobased Benzoxazines from Renewable Resources. ACS Sustain. Chem. Eng. 2014, 2, (12), 2790-2801.

204. Thirukumaran, P.; Shakila Parveen, A.; Kumudha, K.; Sarojadevi, M., Synthesis and characterization of new polybenzoxazines from renewable resources for bio-composite applications. Polym. Compos. 2016, 37, (6), 1821-1829.

205. Amarnath, N.; Shukla, S.; Lochab, B., Harvesting the Benefits of Inherent Reactive Functionalities in Fully Biosourced Isomeric Benzoxazines. ACS Sustain. Chem. Eng. 2018, 6, (11), 15151-15161.

206. Ibeh, C. C., Phenol-Formaldehyde Resins. In Handbook of Thermoset Plastics, $2^{\text {nd }}$ Ed.; William Andrew Publishing, 1998; 23-71.

207. Sakamoto, C.; Nakamoto, Y.; Nemoto, T.; Konishi, G.-i., Synthesis of New Novolacs from Natural Phenolic Compounds. J. Network Polym. Jpn. 2006, 27, (4), 218-220.

208. Li, C.; Fan, H.; Wang, D.-Y.; Hu, J.; Wan, J.; Li, B., Novel silicon-modified phenolic novolacs and their biofiber-reinforced composites: Preparation, characterization and performance. Compos. Sci. Technol. 2013, 87, 189-195.

209. Günther, S.; Lamprecht, P.; Luinstra, G. A., ADMET-Polymerization of Dienes based on Sustainable Chemicals. Macromol. Symp. 2010, 293, (1), 15-19.

210. Le, D.; Samart, C.; Kongparakul, S.; Nomura, K., Synthesis of new polyesters by acyclic diene metathesis polymerization of bio-based $\alpha, \omega$-dienes prepared from eugenol and castor oil (undecenoate). RSC Adv. 2019, 9, (18), 10245-10252.

211. Hu, K.; Zhao, D.; Wu, G.; Ma, J., Synthesis and properties of polyesters derived from renewable eugenol and $\alpha, \omega$-diols via a continuous overheating method. Polym. Chem. 2015, 6, (40), 7138-7148. 
212. Hu, K.; Zhao, D.; Wu, G.; Ma, J., Polyesters derived from bio-based eugenol and 10undecenoic acid: synthesis, characterization, and structure-property relationships. RSC Adv. 2015, 5, (105), 85996-86005.

213. Hu, K., Bio-Based Aromatic Copolyesters: Influence of Chemical Microstructures on Thermal and Crystalline Properties. Polymers 2020, 12, (4), 829.

214. Hu, K.; Zhao, D.; Wu, G.; Ma, J., Bio-based aromatic copoly(ether ester)s with enhanced toughness and degradability: Influence of insertion of phenoxy-ether linkage and eugenolderived composition on properties. J. Polym. Sci., Part A: Polym. Chem. 2016, 54, (14), 21712183.

215. Fajrin, A.; Marliana, S. D.; Handayani, D. S., Synthesis of Eugenol-Lauryl Methacrylate Copolymers via Cationic Polymerization. IOP Conf. Ser. Mater. Sci. Eng. 2018, 349, 012003.

216. Breloy, L.; Ouarabi, C. A.; Brosseau, A.; Dubot, P.; Brezova, V.; Andaloussi, S. A.; Malval, J. P.; Versace, D. L., beta-Carotene/Limonene Derivatives/Eugenol: Green Synthesis of Antibacterial Coatings under Visible-Light Exposure. ACS Sustain. Chem. Eng. 2019, 7, (24), 19591-19604.

217. Burton, G. W.; Ingold, K. U., Autoxidation of biological molecules. 1. Antioxidant activity of vitamin $\mathrm{E}$ and related chain-breaking phenolic antioxidants in vitro. J. Am. Chem. Soc. 1981, 103, (21), 6472-6477.

218. Liu, K.; Madbouly, S. A.; Kessler, M. R., Biorenewable thermosetting copolymer based on soybean oil and eugenol. Eur. Polym. J. 2015, 69, 16-28.

219. Deng, J.; Yang, B.; Chen, C.; Liang, J., Renewable Eugenol-Based Polymeric OilAbsorbent Microspheres: Preparation and Oil Absorption Ability. ACS Sustain. Chem. Eng. 2015, 3, (4), 599-605.

220. Wang, S.; Shuai, L.; Saha, B.; Vlachos, D. G.; Epps, T. H., From Tree to Tape: Direct Synthesis of Pressure Sensitive Adhesives from Depolymerized Raw Lignocellulosic Biomass. ACS Cent. Sci. 2018, 4, (6), 701-708.

221. Molina-Gutiérrez, S.; Dalle Vacche, S.; Vitale, A.; Ladmiral, V.; Caillol, S.; Bongiovanni, R.; Lacroix-Desmazes, P., Photoinduced Polymerization of Eugenol-Derived Methacrylates. Molecules 2020, 25, (15), 3444.

222. Molina-Gutiérrez, S.; Li, W. S. J.; Perrin, R.; Ladmiral, V.; Bongiovanni, R.; Caillol, S.; Lacroix-Desmazes, P., Radical Aqueous Emulsion Copolymerization of Eugenol-Derived Monomers for Adhesive Applications. Biomacromolecules 2020, 21, (11), 4514-4521. 